\title{
Connecting Microscopic Structures, Meso-scale Assemblies, and Macroscopic Architectures in 3D-Printed Hierarchical Porous Covalent Organic Framework Foams
}

Abdul Khayum Mohammed, Saurabh. Usgaonkar, Fayis Kanheerampockil, Suvendu Karak, Arjun Halder, Minakshi Shrikant Tharkar, Matthew A. Addicoat, Thalasseril G. Ajithkumar, and Rahul Banerjee

J. Am. Chem. Soc., Just Accepted Manuscript • DOI: 10.1021/jacs.0c00555 • Publication Date (Web): 11 Apr 2020

Downloaded from pubs.acs.org on April 13, 2020

\section{Just Accepted}

"Just Accepted" manuscripts have been peer-reviewed and accepted for publication. They are posted online prior to technical editing, formatting for publication and author proofing. The American Chemical Society provides "Just Accepted" as a service to the research community to expedite the dissemination of scientific material as soon as possible after acceptance. "Just Accepted" manuscripts appear in full in PDF format accompanied by an HTML abstract. "Just Accepted" manuscripts have been fully peer reviewed, but should not be considered the official version of record. They are citable by the Digital Object Identifier (DOI®). "Just Accepted" is an optional service offered to authors. Therefore, the "Just Accepted" Web site may not include all articles that will be published in the journal. After a manuscript is technically edited and formatted, it will be removed from the "Just Accepted" Web site and published as an ASAP article. Note that technical editing may introduce minor changes to the manuscript text and/or graphics which could affect content, and all legal disclaimers and ethical guidelines that apply to the journal pertain. ACS cannot be held responsible for errors or consequences arising from the use of information contained in these "Just Accepted" manuscripts. 


\section{INTRODUCTION}

The last decade has witnessed a burgeoning interest in porous materials especially in covalent organic frameworks (COFs) because of their low-density, pre-designed structure and atomic precision. ${ }^{1}$ Recently, progress has accelerated as longstanding critical problems such as chemical stability and bulkscale production have been resolved by various strategies. ${ }^{2}$ As a result, these crystalline organic porous architectures have started finding applications in various fields including catalysis, energy storage, drug delivery, and water purifications. ${ }^{3}$ In particular, COFs with exceptional intrinsic micro- or mesoporosity have been investigated for the successful removal of hazardous chemicals from water considering both adsorption and separation methods. ${ }^{4}$ Notably, the adsorption technique is much more reliable, as diffusion of guest molecules through the adsorptive matrix can enhance the interaction and promote effective separation. However, to achieve a high mass transport efficiency through the framework, the intrinsic micro/mesopores should be interconnected with the extrinsic macropores. Such pore connectivity could play a central role in the design of porous materials, which can screen and capture the targets of interest. Inspite of their potential advantages, hierarchical porosity in COFs has not been explored at the highest level. In a recent effort, we induced macroporos- ity within an ordered framework to create a high mass flow through the entire porous covalent network. ${ }^{5}$ The concurrent presence of micro-, meso- and macro-pores endowed fast and efficient removal of different hazardous pollutants, especially persistent organic pollutants (decabromo diphenyl ether) from water. However, their powdered nature and absence of any monolithic form limit their potential large-scale practical application.

The solid-state synthesis of two dimensional (2D) COFs provides monolithic and free-standing macroscopic objects. ${ }^{6}$ However, the obtained high-density material often suffers several disadvantages like volume shrinking and subsequent blocking of their internal pores. The 3D macro-architecture of organic crystalline material like $\mathrm{COF}$, without compromising its hierarchical porous structure, faces several challenges like the synthetic difficulties and poor mechanical stability of the resulted material. Herein, we strategically overcome these issues by employing the 3D-printing technology to induce graphene oxide layers as chemical spacers inside the monolithic COF matrix and thereby, could 3D-print self-supported $\mathrm{COF}$ foams in different shapes from COF precursors. Although COFs were employed in a 3D-printing method previously ${ }^{6 \mathrm{~b}}$ in the current work, we were able to induce hierarchical porosity ranging from $\mathrm{nm}$ to $\mathrm{mm}$ in $3 \mathrm{D}$-printed $\mathrm{COF}$ 

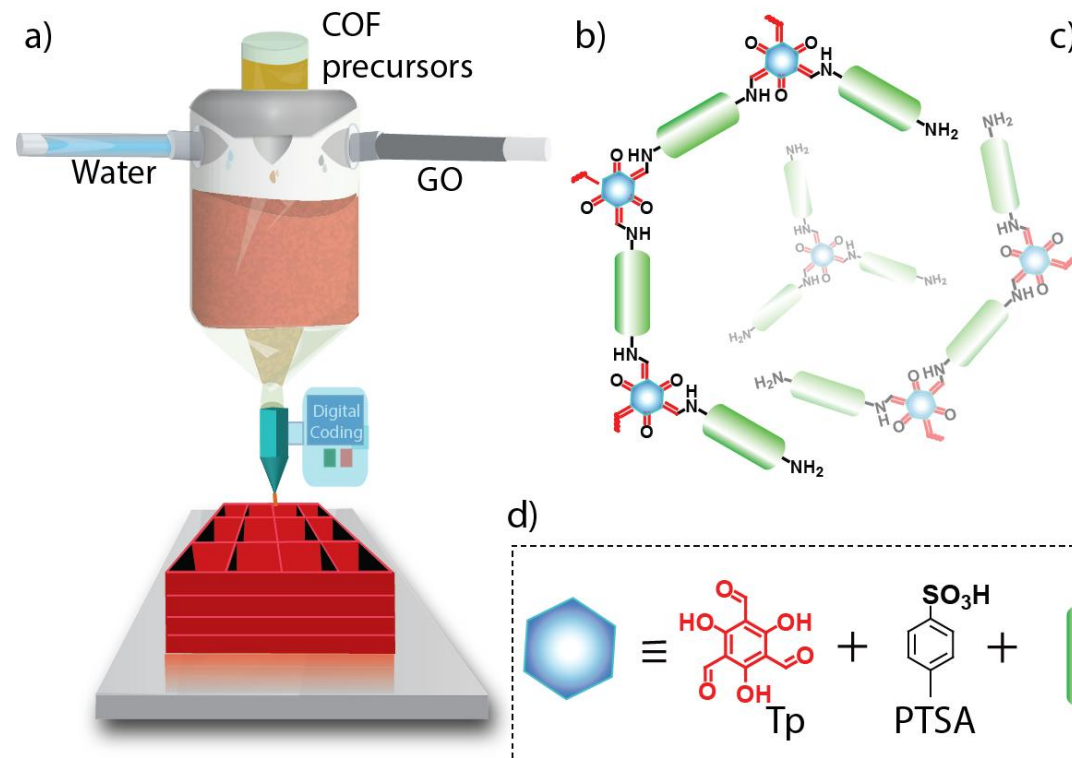

d)
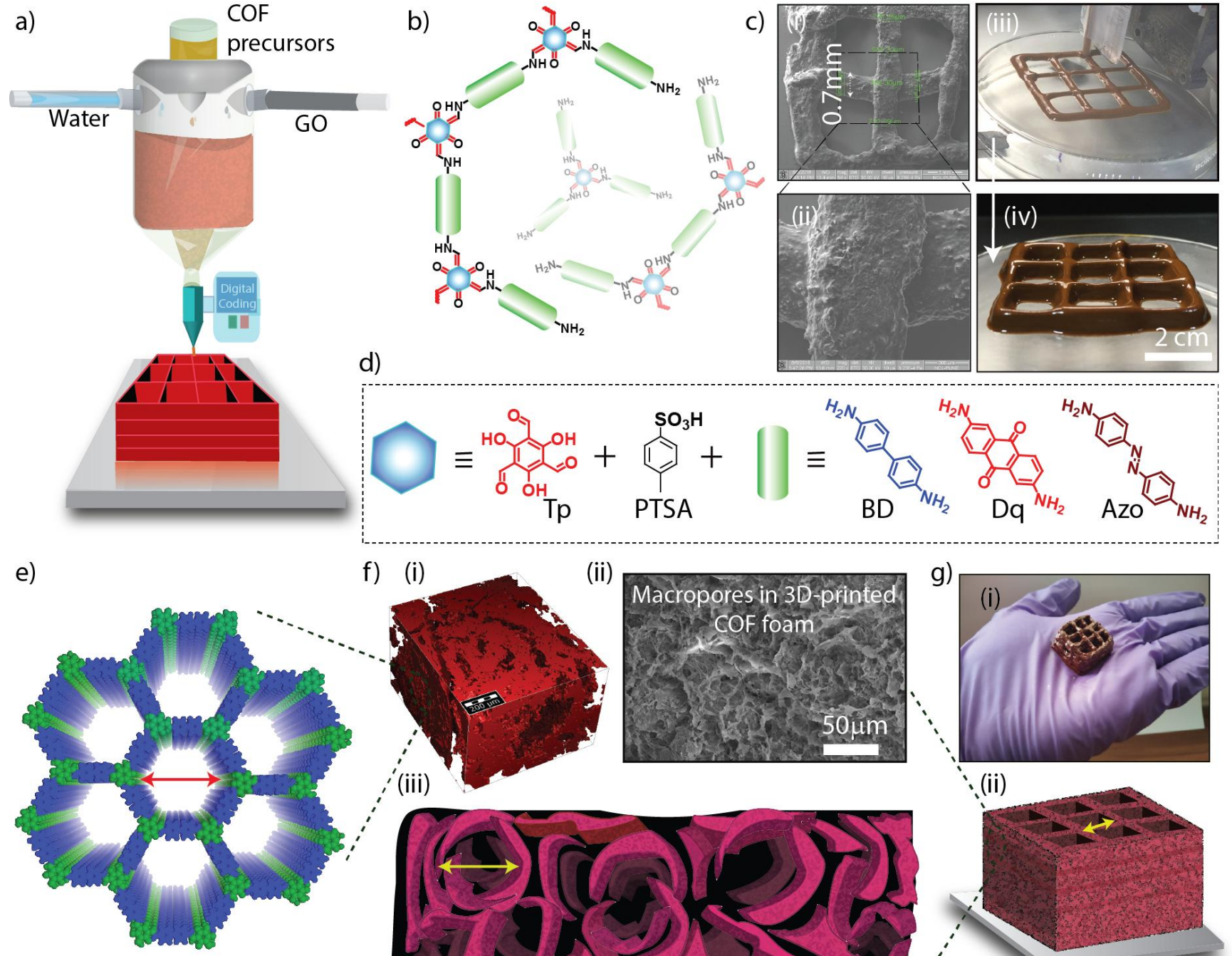

f) (i)

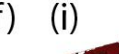

Ordered Microporous

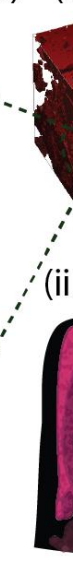
(iii)

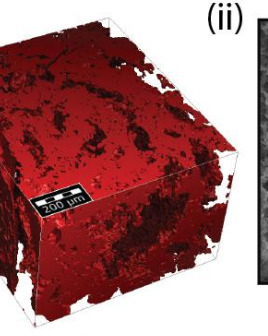

(ii)
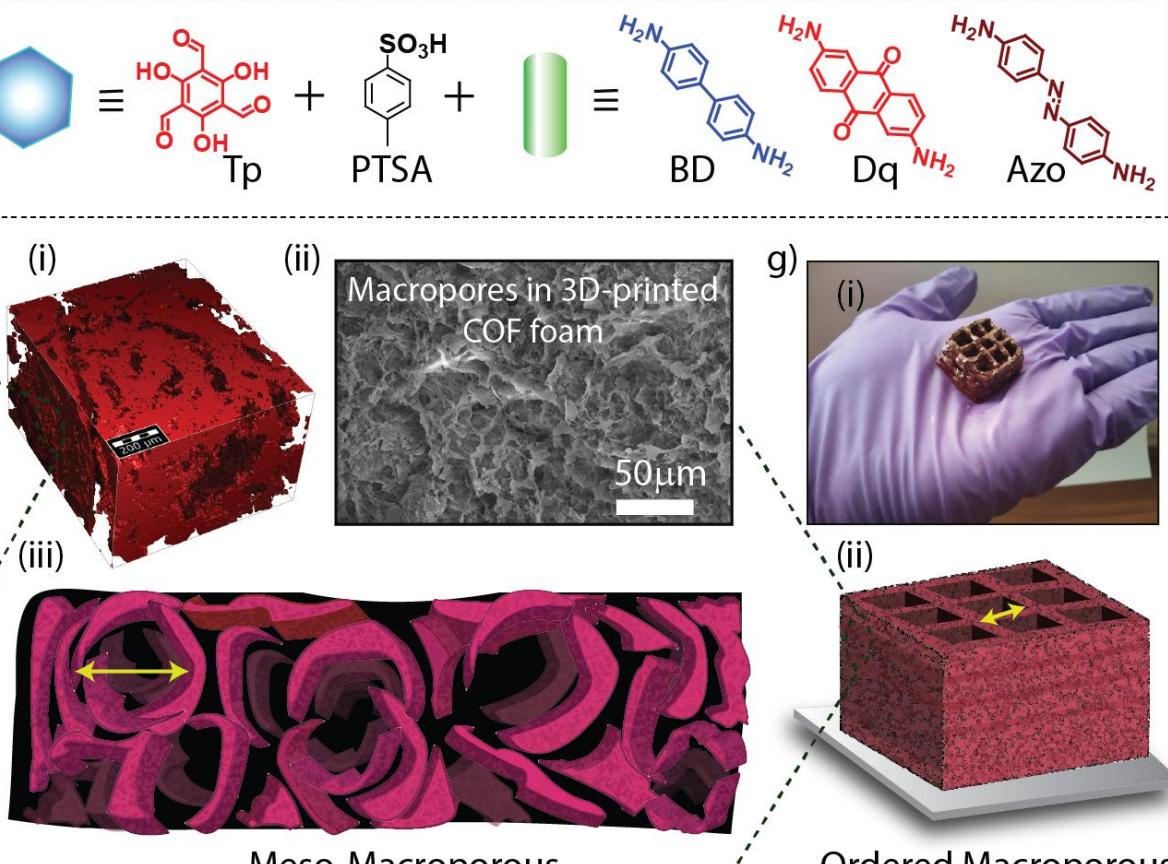

Meso-Macroporous

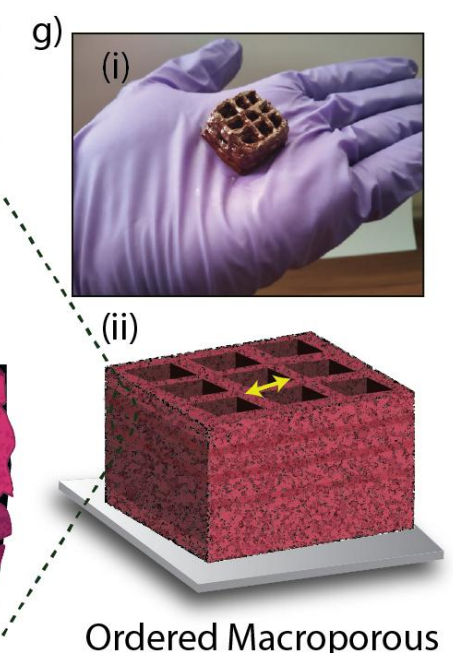

Figure 1. a) Schematic representation of the synthesis and 3D-printing of COF-GO foams. The mixture of COF precursors; water; and graphene oxide forms a hydrogel, which is used for the 3D-printing. b) Schematic representation of the partial frameworks of COFs. At this stage, we expect the formation of partial framework structures or oligomers in the 3D-printing ink. c) (i) \& (ii) The SEM image of 3D-printed millimeter sized COF-GO foam grid with print resolution $0.7 \mathrm{~mm}$ and pore size $\sim 1.5 \mathrm{~mm}$. c) (iii) \& (iv) The digital photographs of 3D-printed centimetre sized COF-GO foam grid. d) The precursors for COF-GO foam synthesis. e) The space-fill model of TpBD COF. f) (i) X-ray microtomography of 3D-printed TpBD foam. It shows the presence of macropores in the COF-GO foam; (ii) SEM image of TpBD foam monolith which displays the macropores in the matrix; and (iii) Graphical representation of the macroporous foam. g) (i) The digital image of 3D-printed self-supported nine pore COF-GO foam grid with the size of $2.3 \times 2.3 \mathrm{~cm}$ and (ii) Graphical representation of the nine pore COF-GO foam grid.

foams. Software-controlled 3D-printing technology has been used for additive manufacturing of the porous materials; although that has mostly been engaged to the fabrication of graphene-based foams, MOF and zeolites. ${ }^{7}$ We presumed that the engineering of 3D COF macrostructures could integrate molecular bodies into prototype devices of complex geometries while keeping their prescribed precise microstructures at the atomic-level. However, 3D-printing ink must possess certain rheological features such as shear-thinning and stable physicochemical properties for the specific build-up of macrostructures. $^{7-8}$ This escalates the challenges to construct $3 \mathrm{D}$ macro-architectures of $\mathrm{COF}$ foams due to the granular nature of the precursor mixture. ${ }^{5}$ Since the precursor mixture is the ink for the 3D printing, the granular nature of the foams suffers from issues like the inability of continuous flow and poor viscosity features. Moreover, the nonadhesive nature of $\mathrm{COF}$ foam crystallites, makes them unsuitable as a material for building desired macrostructures on a large scale $(\mathrm{mm}$ to $\mathrm{cm}$ ). Considering this, we have introduced a novel strategy where graphene oxide (GO) has been used as a foaming agent to engineer crystalline and porous COF foams into 3D-printed geometrical forms. Graphene oxides in water act as a weak hydrogel, which can form intermolecular hydrogen bonds due to the presence of several donor-accepter hydrogen-bonding 
sites (- $\mathrm{COOH} ;-\mathrm{OH}$; -epoxy) at the edges and on the basal planes. ${ }^{7 \mathrm{~d}, 9}$ As a result, we could achieve hierarchical control over the microscopic structure, mesoscale assembly and macroscopic architecture which led to the creation of the first set of crystalline 3D-printable COF-GO foams with a porosity domain ranging from nanometer $\left(10^{-9} \mathrm{~m}\right)$ to millimeter $\left(10^{-3}\right.$ $\mathrm{m})$ [range of a million]. The as-synthesized 3D-printed COFGO foams have further been used as excellent adsorbents (even better than the pristine COF and powdered COF foams, as anticipated) for the rapid removal of different organic pollutants such as methylene blue (MB); basic fuschin (BF), congo red (CR) from water (removal efficiency of $\sim 95 \%$ in less than 10 seconds). Inorganic pollutants like $\mathrm{KMnO}_{4}$ were also removed from water with the quantitative efficiency of 98\% within 30 s. Notably, these COF-GO foams were successfully applied for the removal of bisphenol A (BPA), generally known as a plastic pollutant, from water with $80 \%$ removal efficiency within a minute. ${ }^{10}$ The X-ray microtomography analysis indicates the induction of macroporous volume $(55 \%)$, and good flow of water $\left(1.13 \times 10^{-3} \mathrm{~m} . \mathrm{s}^{-1}\right)$ in $3 \mathrm{D}-$ printed COF-GO foams which results in efficient mass transport.

\section{RESULTS AND DISCUSSION}

The COF precursor paste was synthesized by mixing $1,3,5$ triformylphloroglucinol (Tp: $0.4 \mathrm{mmol}$ ) and diamine (BD: benzidine/ Dq: 2, 6-diaminoanthraquinone/ Azo: 4, 4'Azodianiline: $0.6 \mathrm{mmol}$ ) in the presence of $p$-toluenesulfonic acid (PTSA: $9 \mathrm{mmol})$ and water $(50 \mu \mathrm{L})$ (Figures S1 and S2 and section S-1, Supporting Information). Then, water suspension of graphene oxides $(15 \%$ weight of the precursor aldehyde and amine i.e., $1.8-2 \mathrm{~mL}$ from $16 \mathrm{mg} \cdot \mathrm{mL}^{-1}$ graphene oxide suspension) was introduced as a foaming agent into the precursor matrix to create macropores between the COF crystallites (Figure S6). Keeping the hydrogel features of the COFGO foam precursor paste in perspective, we 3D-printed selfsupported COF-GO foams in different shapes including squares, cubes, grids, and letters by using a softwarecontrolled DIW 3D-printer (Figure 1a-d and Figures S7-S9). Afterwards, the printed objects were kept at $90^{\circ} \mathrm{C}$ at the closed condition for 10-12 h. During the thermal treatment, PTSA controls the imine bond formation thereby rendering high crystallinity to the $\beta$-ketoenamine COF-GO foams. Then the freeze-drying process removed water from the COF-GO foam, which helped in maintaining the porous macrostructure. The dried monolith became very hard and heavy in the presence of PTSA. This was further washed off with water and again subjected to the freeze-drying process. It is worth mentioning that once PTSA is removed from the COF-GO foam monoliths, they become soft and light-weight (they float on water) (Figure S3). The foam monoliths further keep their porosity and crystallinity intact in 3D shapes.

In general, an excellent 3D-printing ink should flow smoothly $\left(5 \mathrm{~mm} \cdot \mathrm{sec}^{-1}\right)$ under an applied pressure with an excellent shear-thinning nature for precise printability. ${ }^{11}$ The plot of the time (15 min) against storage modulus $\left(\mathrm{G}^{\prime}\right)$ and loss modulus $\left(G^{\prime \prime}\right)$ indicates a negligible change in the physical properties (G': 4 to $5 \times 10^{4} \mathrm{~Pa}$; G": 5 to $6 \times 10^{3} \mathrm{~Pa}$ ) of the COF-GO foam precursor paste (Figure $\mathrm{S} 4 \mathrm{c}$ ). The viscosity $v s$ function of shear rate plot reveals the shear-thinning behaviour of the COF-GO foam precursor paste samples (Figure S4a, d, f). The plots show the decrease in viscosity $\left(10^{5}\right.$ or $10^{4} \mathrm{~Pa}$.s to 10 Pa.s) as the shear rate increases from $0.1 \mathrm{sec}^{-1}$ to $100 \mathrm{sec}^{-1}$ which shows the non-Newtonian behaviour of the fluids. ${ }^{11}$ This dynamic change of viscosity under pressure shows their shear-thinning nature and indicates these fluids to be suitable candidates for 3D-printing. During the 3D-printing process, the COF-GO foam precursor paste undergoes various deformations like flowing under pressure and multi layer deposition in different shapes. Hence, it is incredibly challenging to maintain the foam-like nature ( $\geq 55 \%$ void volume throughout the material) in the entire 3D printed object. Thus, the strain sweep experiment was performed on the sample at room temperature at an oscillation frequency of $\omega=1 \mathrm{rad}_{\mathrm{sec}} \mathrm{se}^{-1}$ (Figure $\mathrm{S} 4 \mathrm{~b}$, e, and $\mathrm{g}$ ). At lower values of shear strain (up to $0.3 \%$ ) both $G^{\prime}$ and $G^{\prime \prime}$ are independent of the applied strain and the sample exhibits solid-like behaviour where $G^{\prime}>G^{\prime \prime}$. This reveals that all the samples behave like an elastic solid at rest and can endure the 3D geometry after printing. With further increase in the strain amplitude, above the yield point $(0.35 \%)$, the samples began flowing and exhibiting a shear-thinning behavior (Figure S4b). The multi-cycle step strain oscillatory measurements reveal the self-healing behaviour of the COFGO foam precursor pastes. The three consecutive cycles of step-strain analysis shows $G^{\prime}>G^{\prime \prime}$ at lower strain value $(0.05 \%)$ and $G^{\prime \prime}>G^{\prime}$ at the higher strain (100\%) (Figure S5). All these rheological results indicate the suitability of the precursor-paste for 3D-printing. We could create millimeter to centimetre scale porous architectures of COF-GO foams into a grid or cube or letters by 3D-printing. The 3D-print resolution is up to $0.7 \mathrm{~mm}$ with the pore size of $\sim 1.5 \mathrm{~mm}$ (Figure 1c). We could print up to 15 layers of COF-GO foam in a layer by layer mode and fabricate self-supported 3D-printed nine pores grid with a size of $2.3 \times 2.3 \mathrm{~cm}$ (Figure $1 \mathrm{~g}$ and Figure $\mathrm{S} 8$ and S9). The X-ray computed tomography (micro-CT) features the three dimensional images of 3D-printed interfaces of the COFGO foam (Figure S32). Moreover, we have found that the compressive breaking strain of the TpBD foam is $22.2 \%$ and Young's modulus as $0.259 \mathrm{MPa}$ (Figure S45).

The PXRD profile of the 3D-printed COF-GO foams exhibits high crystallinity and matches well with the simulated PXRD of pristine COFs/ COF foam powders. The first intense peak, originating from the $\langle 100\rangle$ plane at $3.8^{\circ} ; 3.7^{\circ} ; 3.5^{\circ}$ and $(2 \theta)$ correspond to the TpBD, TpDq, and the TpAzo foams respectively. A weak and broad peak is visible at an angle of $26-27^{\circ}$ (20) which signifies the $\pi-\pi$ stacking of hexagonal COF layers in the foam matrix (Figure 2a and Figure S10). Additionally, the complete removal of PTSA is evident from the PXRD patterns and also from the absence of the signature stretching peak at $815 \mathrm{~cm}^{-1}$ in the FT-IR (Figures S11 and S13). Moreover, FT-IR signifies the presence of $C=C\left(1560-1570 \mathrm{~cm}^{-1}\right)$, $\mathrm{C}=\mathrm{O} \quad\left(1590-1620 \mathrm{~cm}^{-1}\right)$ and $\mathrm{C}-\mathrm{N}$ bonds $\left(1220-1250 \mathrm{~cm}^{-1}\right)$ referring to the formation of the $\beta$-ketoenamine network within the foam (Figure S12). ${ }^{13} \mathrm{C}$ solid-state NMR spectroscopy confirms the atomic level constructions of the COF-GO foam backbone. A broad peak resonance at 183-186 ppm for all COF-GO foams indicates that the carbon atom from $\mathrm{C}=\mathrm{O}$ functionality originated due to the keto-enol tautomerism. ${ }^{2 \mathrm{a}}$ The COF-GO foams also display the enamine and $\alpha$-enamine carbon positions at 145-147 and 107 ppm respectively (Figure $2 \mathrm{k}$ and Figure S14). Additionally, the TGA analysis shows that the thermal stability of COF-GO foams up to $400^{\circ} \mathrm{C}$ with the retention of $90 \%$ mass (Figure S16).

The incorporation of macropores in the 2D network was visible in the SEM images of the TpBD foam (Figure $2 \mathrm{f}-\mathrm{g}$ and Figures S17 and S18). A diligent observation of the SEM 


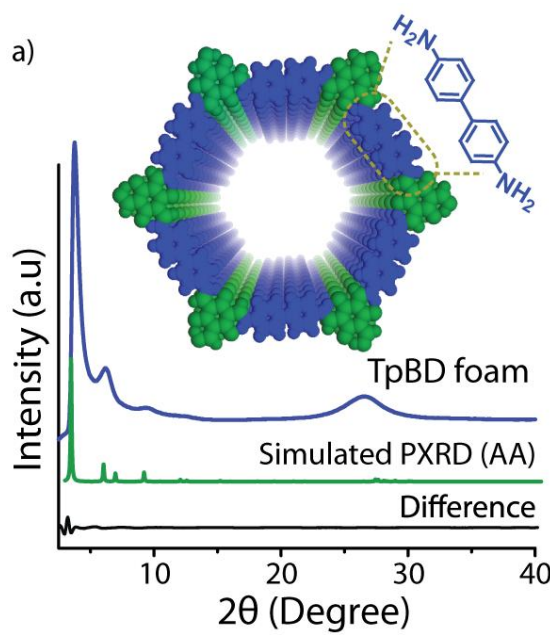

b)

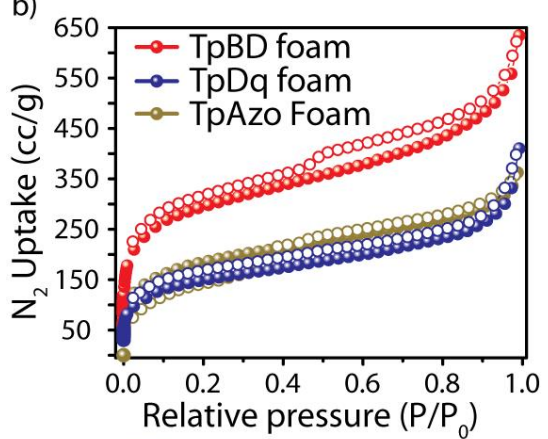

k)

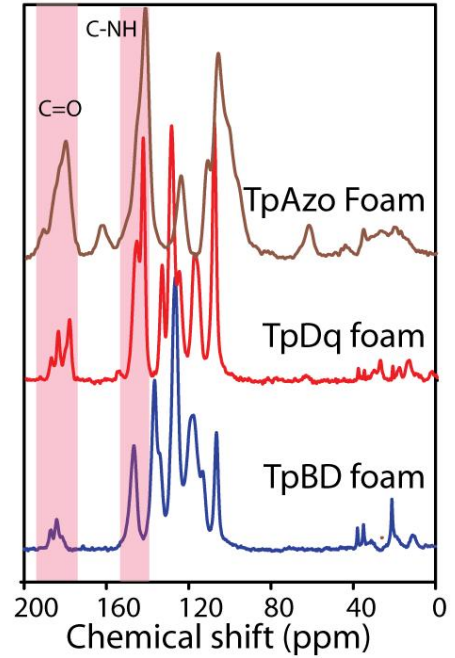

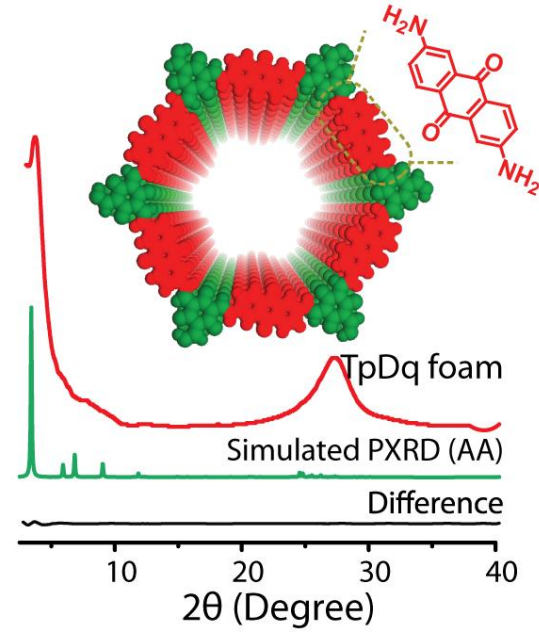

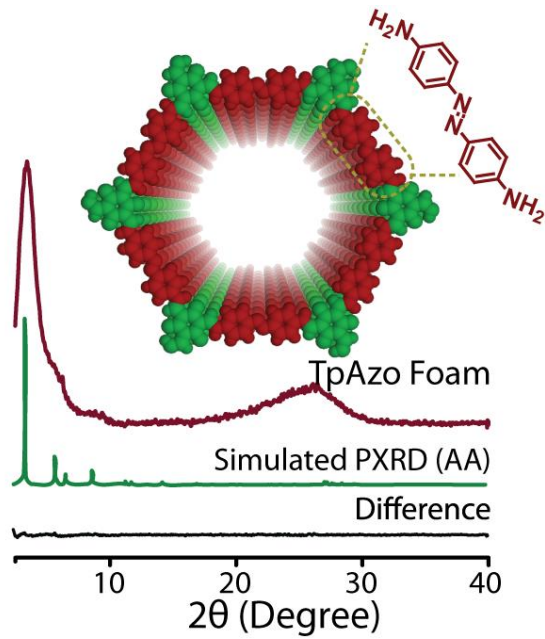

c)
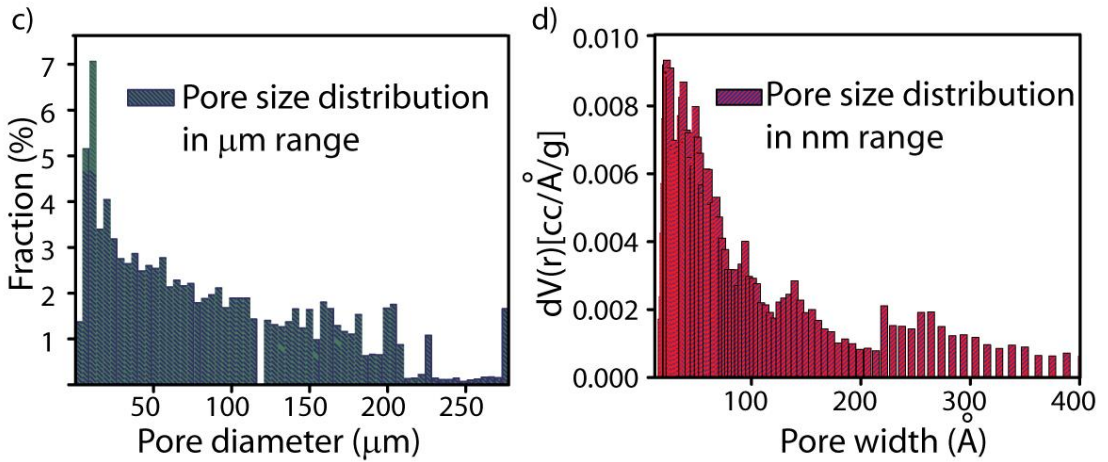

e)
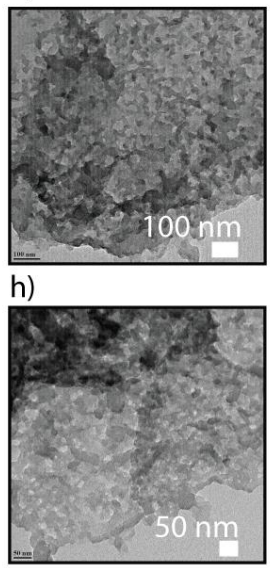

f)

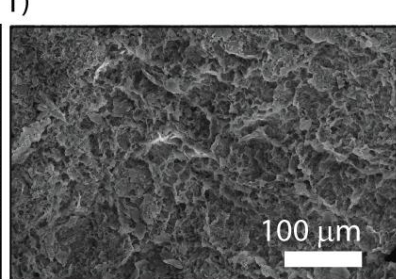

g)

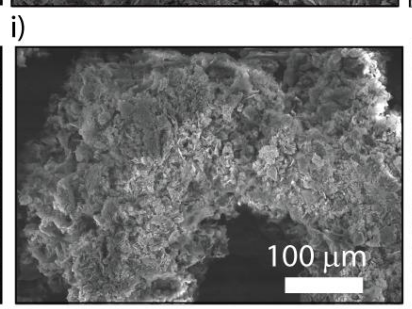
j)
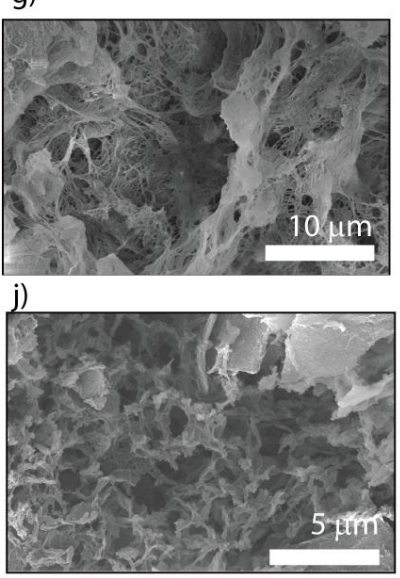

Figure 2. a) PXRD profiles of 3D-printed COF-GO foams. b) $\mathrm{N}_{2}$ gas adsorption of 3D-printed COF-GO foams. c) Pore size distribution analysis of TpBD foam from X-ray tomography reveals the macroporous nature of the foam. d) NLDFT pore size distribution of TpBD foam from $\mathrm{N}_{2}$ adsorption analysis. It indicates the micro $(2.2 \mathrm{~nm}$ ) and mesoporous nature of the foam. e and $\mathrm{h}$ ) TEM of TpBD \& TpDq foams respectively. $f \&$ g) FESEM of TpBD foam. i) and j) FESEM of TpDq and TpAzo foams, respectively. $k){ }^{13} \mathrm{C}$ CP-MAS solid-state NMR of COF-GO foams.

images displays the presence of several macropores ranging from $5 \mu \mathrm{m}$ to $100 \mu \mathrm{m}$ inside the foam matrix. The macropores of $\mathrm{TpBD}$ foam are occupied with crystalline COF ribbons along with the thin sheets of graphene oxide. Whereas, the COF crystallites present in the TpDq foam exhibit a sheet-like morphology $(1-2 \mu \mathrm{m})$ with the macropores ranging between 5-100 $\mu \mathrm{m}$ (Figure 2i and Figure S19). Again, the TpAzo foam exhibits the morphology of ribbons (length of $1-2 \mu \mathrm{m}$ ) which are surrounded by thin sheets of graphene oxide (Figure $2 j$ and Figure S20). The TEM images support the ribbon-like mor- phology of COF-GO foams along with the large lateral sized graphene oxide layers $(\sim 3 \mu \mathrm{m})$ (Figure $2 \mathrm{e} \& \mathrm{~h}$ and Figure S21).

We have performed confocal fluorescent microscopic 3D imaging of COF-GO foams for substantiating the porous features of the as-synthesized materials. The confocal fluorescence microscopic images of $\mathrm{TpBD}$ and $\mathrm{TpDq}$ foams after staining with fluorescent Rhodamine $\mathrm{B}(\mathrm{RhB})$ solution suggest a scattered particle morphology of both materials which contains micrometer-sized pores $(\sim 5 \mu \mathrm{m})$. The confocal 

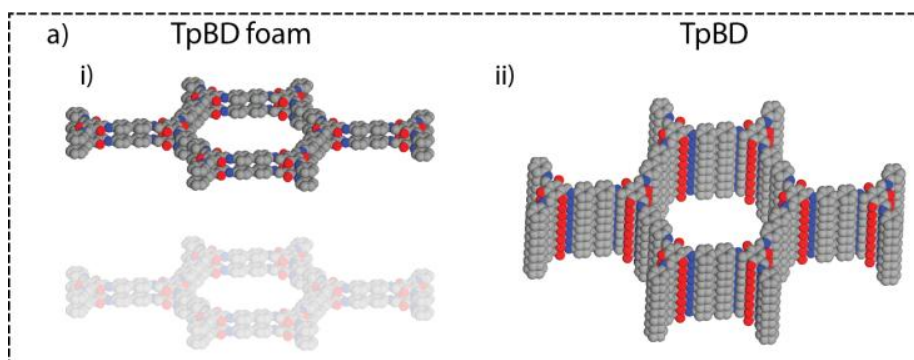

b) i)

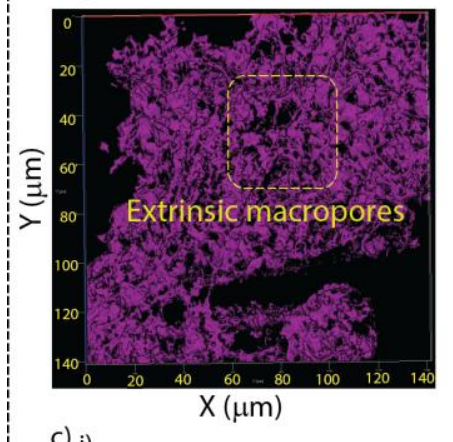

1"
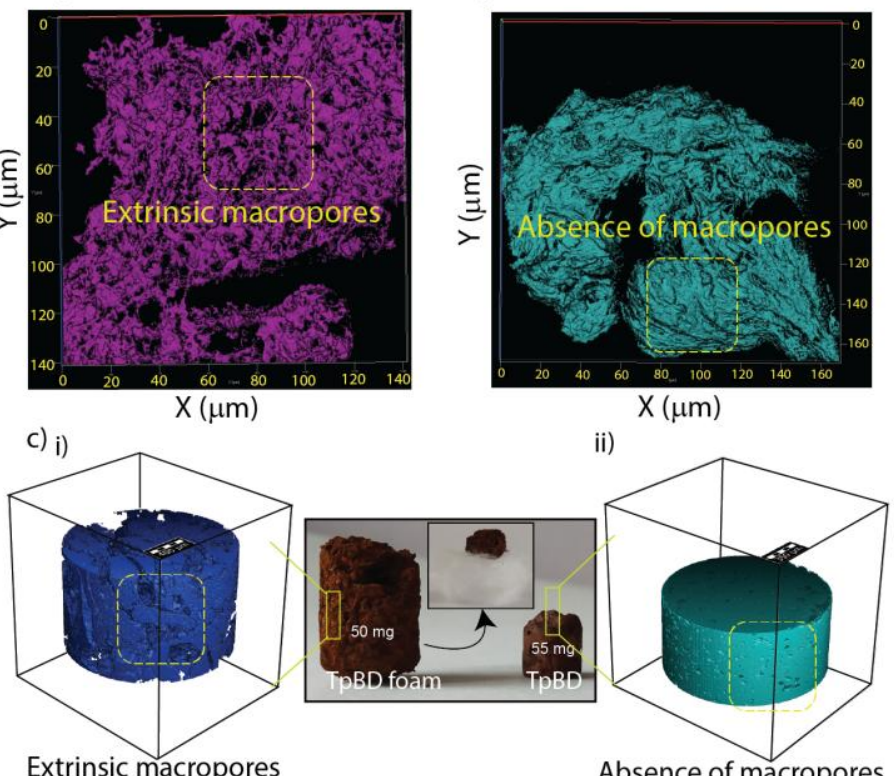

Extrinsic macropores $55 \%$ void volume

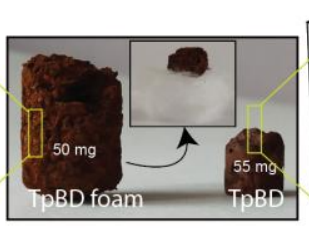

ii)

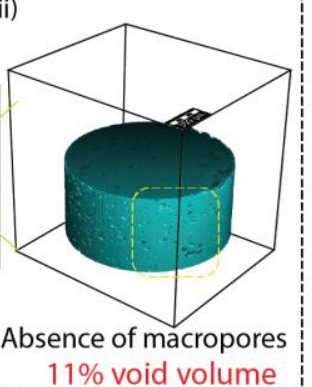

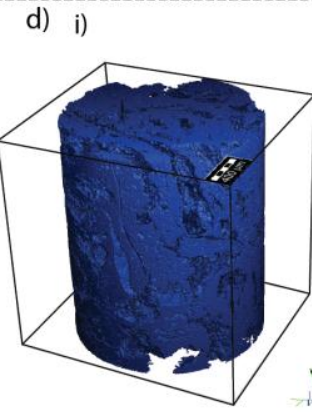

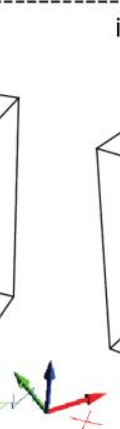

ii)

e) i)

ii)
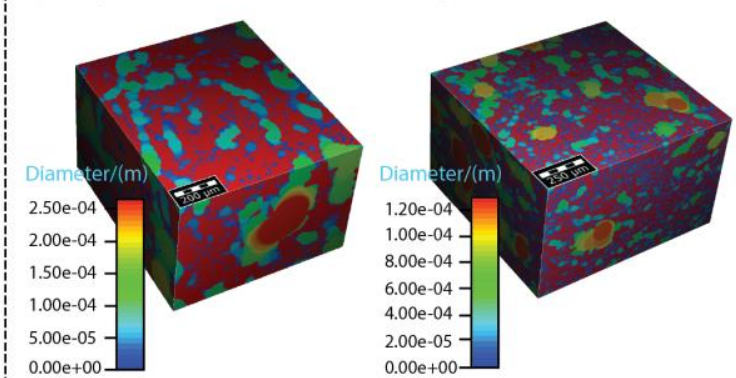

f) i)

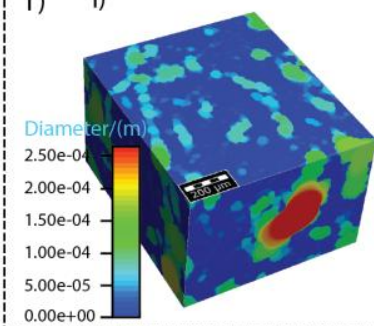

ii)

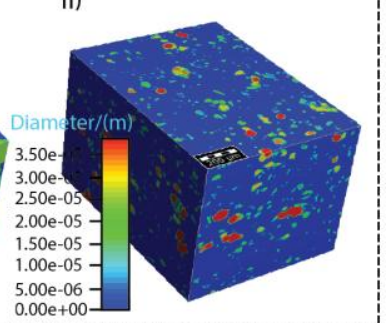

Figure 3. a) (i) The space-fill model of the TpBD foam (manually represented) and (ii) the space-fill model of the TpBD COF. b) Confocal fluorescence images of TpBD (i) foam \& (ii) COF. This indicates the presence of the extrinsic macropores in the COF-GO foam, whereas, any macropores are absent in the COF. c) 3D tomographic images of TpBD (i) foam \& (ii) COF (inset: digital photographs of foam and COF). Tomography images suggest the macroporous nature of the COF-GO foam. Due to the large void volume, the size of the foam monolith is larger than the COF with the same gravimetric weight. d) 3D X-ray tomographic images of (i) TpBD foam \& (ii) TpDq foam. e) 3D X-ray tomographic pore size distribution (including solid materials) of (i) TpBD foam \& (ii) TpDq foam. f) 3D X-ray tomographic pore size distribution (only pores) of (i) TpBD foam \& (ii) TpBD COF.

microscopic images of the COF-GO foams display plenty of extrinsic pores with poorly interconnected particles. On the other hand, the pristine COF particles feature only a few macropores (Figure 3a-b). The presence of extrinsic macropores in the pristine COFs is sharply reduced, especially for the sheet-like morphology of TpDq (Figure S22).

Microscale X-ray computed tomography was engaged to unveil the 3D macrostructures of 3D-printed $\mathrm{TpBD}$ and $\mathrm{TpDq}$ foams possessing hierarchical pores ranging from $\mathrm{nm}$ to $\mu \mathrm{m}$ scales (Figure 3d and Figure S23). The tomography highlights the three-dimensional morphological features of the COF-GO foam monoliths and the presence of interconnected extrinsic macropores $(2-200 \mu \mathrm{m})$ (Figure 3c-f and Figures S24-S27). The presence of ordered lamellar or ribbon-like COF crystallites (up to $200 \mu \mathrm{m}$ ) within the specimen indicates that the 3D objects $(1.0 \times 1.0 \times 0.5 \mathrm{~mm})$ of foams are made up of small crystallites $(1-5 \mu \mathrm{m})$ having thin layers of two-dimensional microporous COF nanosheets. The vertical and horizontal cross-sectional view of the foams displays the presence of macropores $(2-200 \mu \mathrm{m})$ not only on the surface but also within the entire foam matrix. We have analysed the pore size distribution of the solid matrix, considering the pores as spheres and fitting them into the empty volume of the foam. The TpBD foam exhibits a macroporous void volume of 55\% of the entire matrix which is 5 times larger than the corresponding pristine TpBD COF (11\% of the macroporous volume) (Figure S23 and S24). 90\% of the macropores range between 30-180 $\mu \mathrm{m}$ in diameter in the COF-GO foam, whereas the pristine COF contains macropores ranging from 2-37 $\mu \mathrm{m}$ only (Figure 2c and Figures S24, S26 and S27). The $\mathrm{TpDq}$ foam has a macroporous volume of $74 \%$ of the the entire matrix and out of this, $90 \%$ of these macropores are in the diameter range of $10-80 \mu \mathrm{m}$ (Figures S25 and S26). The $3 \mathrm{D}$ tomographic images of pristine $\mathrm{TpBD}$ and $\mathrm{TpDq} \mathrm{COFs}$ show the absence of interconnected macropores which results in void-free solid structures. Therefore, the solid-state synthesis of COFs would only provide a poorly macroporous dense structure associated with intrinsic microporosity (in 2-2.5 nm range) (Figure S43 and S44). On the other hand, the strategic incorporation of the macroporous volume in the COF-GO foam aids the adequate access of the active adsorbent sites inside the COF crystallites. Additionally, we have estimated the macroporous specific surface area of COF-GO foams in the PoroDict module of X-ray tomography. We could find the 

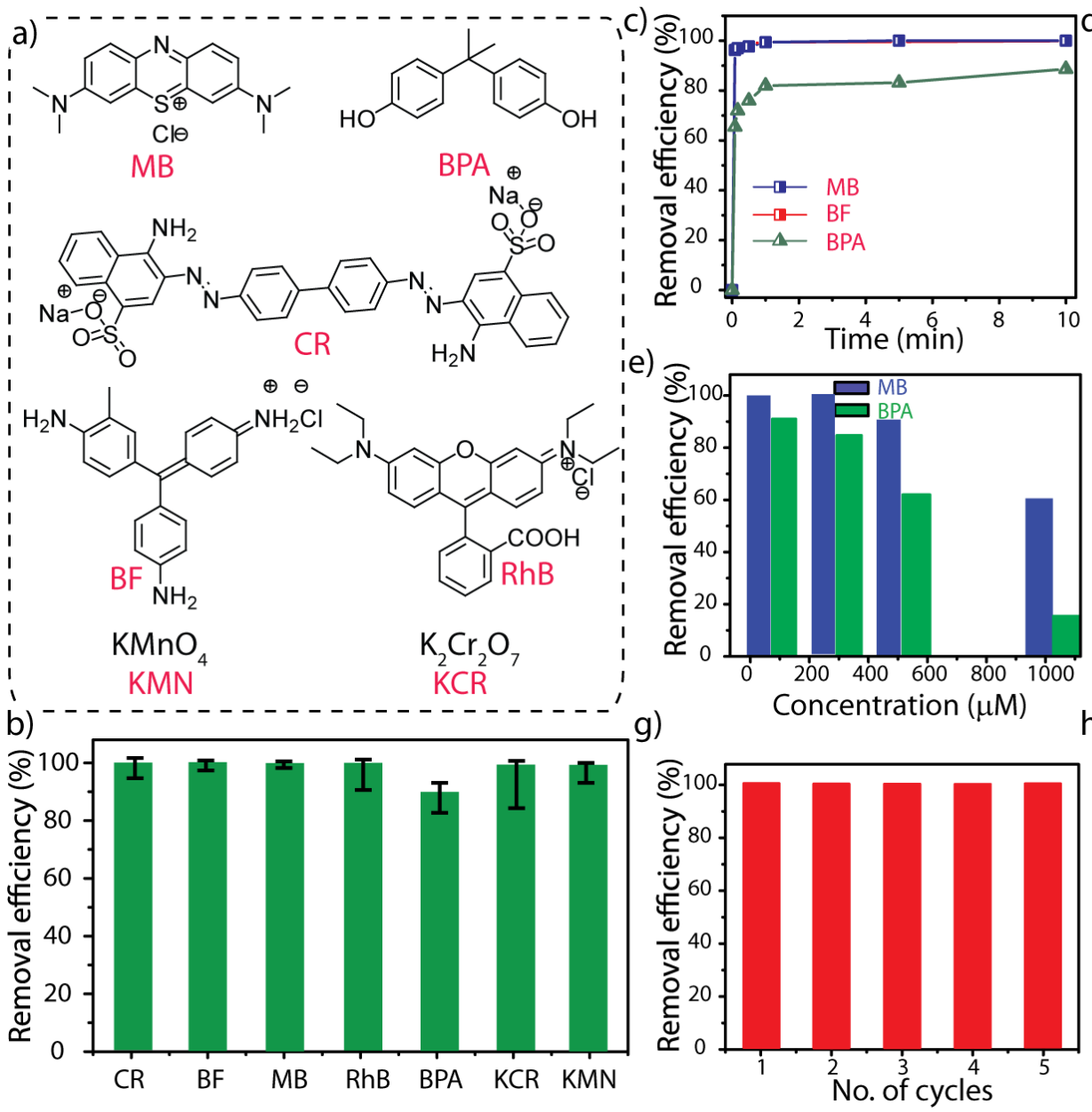

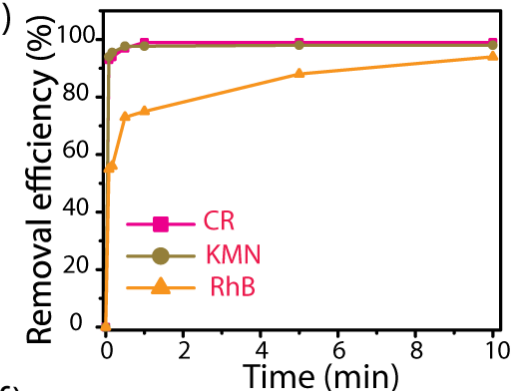

f)

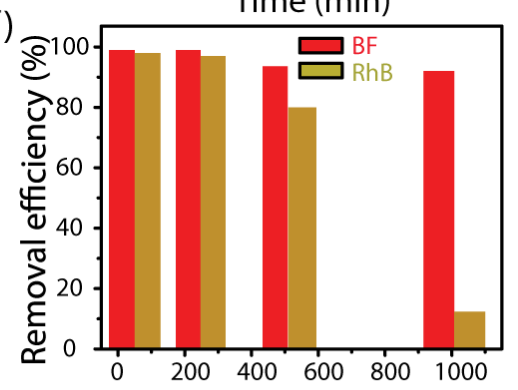

h)

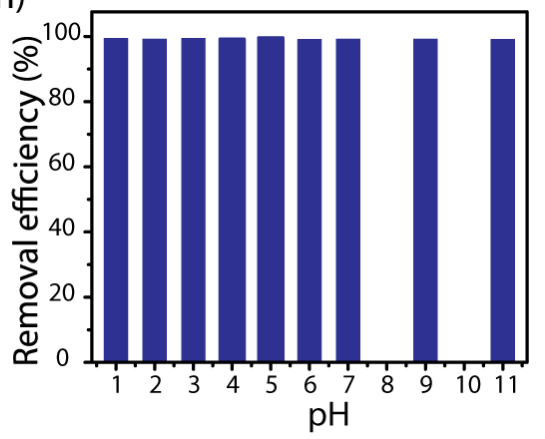

Figure 4. a) The Chem Draw representations of pollutant molecules considered for adsorption studies. b) The removal efficiency of pollutant molecules by TpBD foam. c \& d) The kinetic analysis of adsorption studies. e \& f) Pollutant removal efficiency at various pollutant concentration. g) Recyclability test. h) The removal efficiency of the TpBD foam against MB at different pH ranges (1 to 13) All the studies regarding the pollutant removal are related to TpBD foam, if not mentioned.

macroporous specific surface area of COF-GO foams (TpBD foam: $44414 \mathrm{~m}^{2} / \mathrm{m}^{3}$ and TpDq foam: $\left.108110 \mathrm{~m}^{2} / \mathrm{m}^{3}\right)$ is higher than the corresponding pristine COFs (TpBD COF: 28278 $\mathrm{m}^{2} / \mathrm{m}^{3}$ and TpDq COF: $38338 \mathrm{~m}^{2} / \mathrm{m}^{3}$ ) (Figure S31).

The 3D-printed COF-GO foams reported, herein, posses continuous porosity ranging from 3D-printed ordered macropores $(1.5 \mathrm{~mm}$ to $2 \mathrm{~cm})$ to disordered macro and meso pores $(50 \mathrm{~nm}$ to $200 \mu \mathrm{m})$ and to reticular micropores $(2-2.2 \mathrm{~nm}$ ) (Figure 1e-g). The $\mathrm{N}_{2}$ adsorption analyses of TpBD; TpDq; and TpAzo foams provide critical information related to their micro and mesoporosity and the ordered nature of the pore channels (Figure 2b and Figure S15 and Figure S46). Despite the presence of graphene oxides, the TpBD, TpDq, and TpAzo foams show BET surface areas of 971,500 and $624 \mathrm{~m}^{2} \cdot \mathrm{g}^{-1}$ respectively (Figure $2 \mathrm{~b}$ ). The slight drop in the surface area compared to the pristine COFs could be due to the disordered mesoscale assembly of the COF crystallites in foams. The small hysteresis loop present in each isotherm could be an indication of the extrinsic meso and macroporous nature of a 3D-architectured foam. The pore size distribution, calculated using the NLDFT model, also refers to the presence of regular $\sim 2 \mathrm{~nm}$ pores hence reflecting intrinsic ordered microporosity of the COF-GO foams (Figure 2d and Figure S15). The pore size distribution of TpBD, TpDq and TpAzo foams ranging from 5-400 and 5-150 $\AA$ show the large disordered mesoscale assembly of COF crystallites in foams. The higher surface area of TpBD foam could be due to the ordered pi-pi stacking of the 2D COF layers that renders high crystallinity. The sharp $<100>$ peak in the PXRD profile of TpBD foam confirms its higher crystallinity compared to the other two foams.

During the foam synthesis, the mixing of amine and PTSA results in the formation of amine-PTSA salts via $\mathrm{N}_{\text {amine }}-\mathrm{H}^{\cdots} \mathrm{O}_{\text {acid }}\left(\mathrm{D}_{\text {avg }}=2.78-2.91 \AA, d_{\text {avg }}=2.06-2.19 \AA\right)$ hydrogen bonding between the amine $\left(-\mathrm{NH}_{3}{ }^{+}\right)$of the diamine molecules and the sulfonate groups $\left(-\mathrm{SO}_{3}{ }^{-}\right)$from the PTSA catalyst. ${ }^{12}$ The formation of these salts will slow-down the reaction kinetics of imine linkage with the $\mathrm{C}_{3}$ symmetric $\mathrm{Tp}$ moieties. The presence of graphene oxide aids to create selfassembly within the precursor paste due to the inter-molecular $\mathrm{O}-\mathrm{H} \cdots \mathrm{O}$ hydrogen bonding between graphene oxide layers in water. As a result, several vertical and horizontal alignments of graphene oxide layers create meso and macroscopic spaces inside the COF matrix (Figure S33).

In contrast to the membrane, photocatalysis, and oxidative degradation methods for water purifications, adsorption techniques are cost-effective and efficient. ${ }^{13}$ The 3D-printed COFGO foams, consisting of hierarchically connected pores, noncovalently interact with the adsorbate molecules during the water flow (containing different pollutants) through the solid matrix (i.e. physisorption). DFTB modelling shows that 

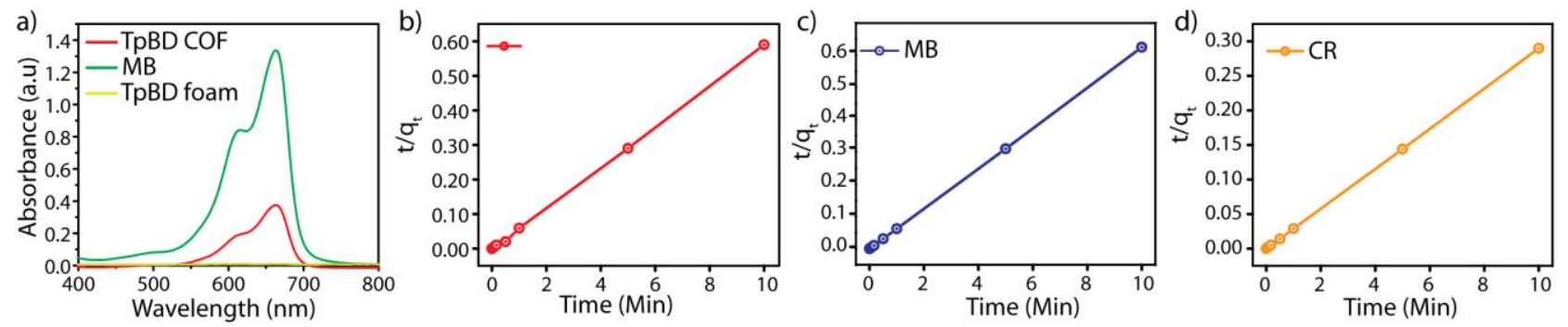

e)

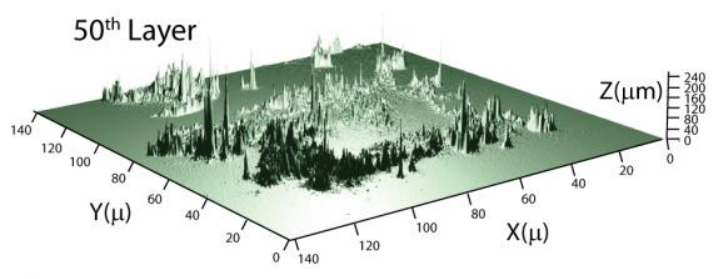

f)

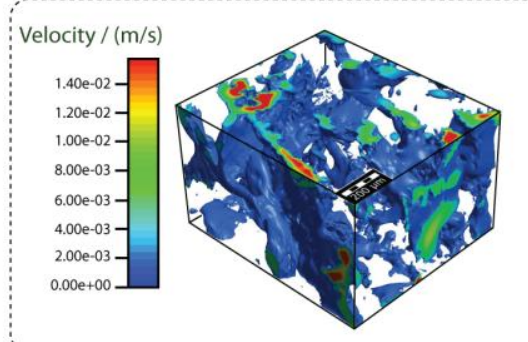

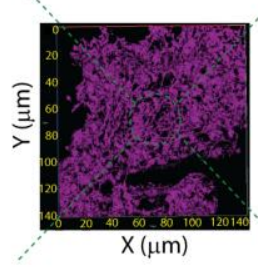

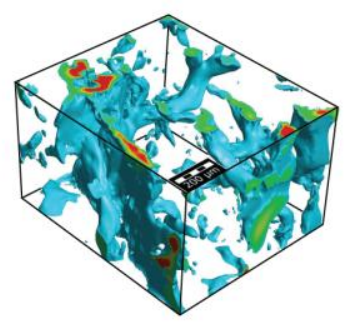

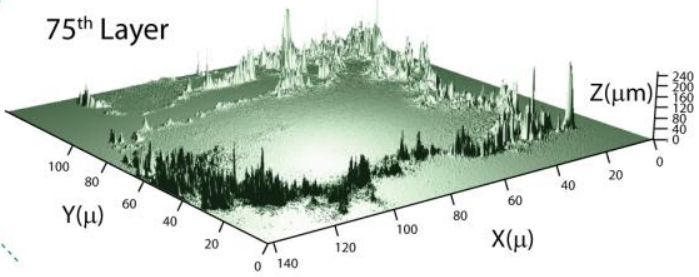

g)

Figure 5. a) UV spectra of MB adsorption studies. b-d) The adsorption kinetic analysis of the different pollutant molecules with the $\mathrm{TpBD}$ foam in water. e) $2.5 \mathrm{D}$ fluorescence confocal images of the TpBD foam $\left(50^{\text {th }}\right.$ and $75^{\text {th }}$ layers $)$ show dispersive adsorption of $\mathrm{RhB}$ molecules in each of the 2D layers. f) X-ray tomographic water-flow simulation studies of the TpBD foam. g) The plot of position (micron) $v s$ pressure drop $(\mathrm{Pa})$ from the water-flow analysis of the TpBD foam.

molecules interact with both the pore wall of the COF as well as the periphery of the foam crystallites (Figure S42). All the three different COF-GO foams (TpBD; TpDq; and TpAzo foams) have been used for the adsorption of methylene blue (MB); congo red (CR); Rhodamine B (RhB); Basic Fuschin (BF); Bisphenol-A (BPA); $\mathrm{KMnO}_{4}(\mathrm{KMN})$ and $\mathrm{K}_{2} \mathrm{Cr}_{2} \mathrm{O}_{7}$ (KCR) from water (Figure 4a-b, Figures S34 and S35) Among the three COF-GO foams, the TpBD foam exhibits the highest pollutant removal efficiency within $30 \mathrm{~s}$. Notably, the adsorption kinetic analysis shows that the TpBD foam performs rapid removal (MB 98\%; CR 97\%; RhB 73\%; BF 99\%; $\mathrm{BPA} \sim 76 \%$; KMN: $\sim 98 \%$; and $\mathrm{KCR} \sim 55 \%$ within 30 s) of different pollutants from water (Figure $4 \mathrm{c}-\mathrm{d}$ and Figure S38). Meanwhile, the adsorption analysis of $\mathrm{TpDq}(\mathrm{MB} \sim 99 \%$; $\mathrm{RhB}$ $\sim 95 \%$; BF 99\%; BPA 66\%; KMn 73\%; and KCR $62 \%$ within 60 s) and TpAzo (CR 88\%; $\mathrm{MB} \sim 98 \%$; RhB $85 \%$; BF 99\%; BPA 85\% within 60 s within 60 s) foams show good removal efficiency towards various pollutant molecules in water. Although all the COF-GO foams display good adsorption behaviour towards the pollutant molecules, herein, we have analyzed in-detail adsorption studies with the TpBD-foam considering its rapid uptake behaviour (>90\% within $60 \mathrm{~s})$. The excellent and efficient removal of $\mathrm{MB}$ (>99\% in less than a minute) by $\mathrm{TpBD}$ foam at various $\mathrm{pH}$ ranges (calculated from 1 to 13) signifies the potential utility of the material in real-life conditions (Figure $4 \mathrm{~h}$ and Figure S36). The recyclability (5 times) of the TpBD foam for $\mathrm{MB}$ dye indicates the pollutants are only physically adsorbed, and they can be desorbed back from the foam-surface upon treat- ment with a suitable organic solvent (Figure 4g). After each cycle of the adsorption, the COF-GO foam was dipped in acetone solvent in order to desorb the pollutant molecules. After the desorption, we have removed the acetone from the COF matrix by applying a vacuum and then reused the same for the next cycle. We have measured the removal efficiency of the molecular pollutants from the water between 5 to $600 \mathrm{~s}$ time interval. The rapid uptake nature is reflected in the pseudo-second-order rate constants $\left(k_{\text {obs }}\right.$ ) of the TpBD foam. ${ }^{14} \mathrm{We}$ found the $k_{\text {obs }}$ of different pollutants such as MB: 10.2 g.mg ${ }^{1} \cdot \mathrm{min}^{-1}$; CR: 6.6 g.mg ${ }^{-1} \cdot \mathrm{min}^{-1}$; RhB: 0.3 g.mg ${ }^{-1} \cdot \mathrm{min}^{-1}$; BF: 0.001 g.mg ${ }^{-1} \cdot \mathrm{min}^{-1}$; BPA: 1.5 g.mg ${ }^{-1} \cdot \mathrm{min}^{-1}$; KMN: 43.8 g.mg ${ }^{-1} \cdot \mathrm{min}^{-1}$ and KCR: 4.6 g.mg $\mathrm{mg}^{-1} \cdot \mathrm{min}^{-1}$ (Figure 5b-d and Figure S39). Importantly, the kinetic removal efficiency of dangerous plastic pollutants like BPA in water (at $50 \mu \mathrm{M}$ ) exceeds the performance of many amorphous polymers and carbon-based materials. ${ }^{15}$ BPA molecules are adsorbed on inner pore walls of the COF crystallites due to the smaller molecular size. The experimental observations of the different concentration adsorption studies $(50 ; 100 ; 250 ; 500 \& 100 \mu \mathrm{M})$ suggest effective removal efficiencies of molecular pollutants even at higher concentrations. It is worth mentioning, the pollutant removal efficiency of $\mathrm{MB}$ (at $500 \mu \mathrm{M}$ ) and $\mathrm{BF}$ (at $1000 \mu \mathrm{M}$ ) is $\geq 90 \%$, whereas for BPA (at $250 \mu \mathrm{M}$ ); RhB (at $500 \mu \mathrm{M}$ ); and $\mathrm{KMN}$ (at $1000 \mu \mathrm{M}$ ) the pollutant removal efficiency is $\geq 80 \%$. The uptake maxima of TpBD foam towards different pollutants have been experimentally calculated (MB:194 mg. $\mathrm{g}^{-1}$; BF: $310 \mathrm{mg} \cdot \mathrm{g}^{-1}$ at $1000 \mu \mathrm{M}$ and RhB:194 mg. $\mathrm{g}^{-1}$; BPA: $69.6 \mathrm{mg} \cdot \mathrm{g}^{-1}$ at $500 \mu \mathrm{M}$ ) from the high concentration of solutions (Figure 
4e-f and Figure S37). The obtained experimental uptake maximum of MB (194 mg. $\left.\mathrm{g}^{-1}\right)$ is almost double that of the previously reported COF-GO foams (108 mg. $\left.\mathrm{g}^{-1}\right)$. We believe, the excellent connection between the macro; meso; and micropores in these 3D-printed foams is responsible for the high pollutant adsorption capacity.

Both the TpBD foam and the TpBD COF (prepared by PTSA assisted solid-state synthesis) were tested for the removal of MB from water. We have noted that the TpBD foam removed $98 \%$ of pollutant (MB) within $30 \mathrm{~s}$, whereas the TpBD COF could only remove $73 \%$ of $\mathrm{MB}$ from water even after 5 minutes (Figure 5a). Their highly stacked crystallites with nonmacroporous nature block the infiltration of the pollutant solution into the inner surface of intrinsic microporous walls. This hindered transport of solution further promotes the excessive adsorption of pollutant molecules at the surface which subsequently blocks the accessible adsorbent area (inner core). We have performed $2.5 \mathrm{D}$ confocal microscopic analysis to investigate the adsorption of molecules into the bulk foams (Figure 5e, Figures S40 and S41). The experiment reveals that the $\mathrm{RhB}$ molecule is adsorbed at different 2D layers of the foam monolith (100 numbers of stacked 2D layers along the $\mathrm{Z}$-axis). The $2.5 \mathrm{D}$ confocal images of different layers $\left(25^{\text {th }}\right.$; $50^{\text {th }} ; 65^{\text {th }}, 75^{\text {th }} ; 85^{\text {th }}$; and $100^{\text {th }}$ ) of TpBD foam display dispersive adsorption nature of the dyes inside the foam monolith.

We have investigated the water flow analysis in Flow-Dict module by using 3D X-ray microtomography (Figure 5f-g and Figures S28-S30). The water accessibility into the inner core of the foam matrix illustrates the possible solid (COF-GO foam)-pollutant solution interactions. A segment of the 3D tomography model of COF-GO foam has been employed forwater flow simulation along Z-axis with a pressure of 20 $\mathrm{Pa}$. It provides the average flow velocity of the TpBD foam in the X-direction is $1.3 \times 10^{-5} \mathrm{~m} . \mathrm{s}^{-1}$, the Y-direction is $2.96 \times 10^{-}$ ${ }^{5} \mathrm{~m} . \mathrm{s}^{-1}$ and the Z-direction is $1.15 \times 10^{-3} \mathrm{~m} . \mathrm{s}^{-1}$. The overall average velocity distribution has been estimated as $1.13 \times 10^{-3}$ $\mathrm{m} . \mathrm{s}^{-1}$. The TpDq foam also displays a water flow rate with an average velocity distribution of $1.53 \times 10^{-4} \mathrm{~m} . \mathrm{s}^{-1}$ which is less than the average flow velocity of the TpBD foam. This could be due to sizeable macroporous distribution in the $3 \mathrm{D}$ blocks of the TpBD foam and indicates that the velocity distribution of water flow $\left(2 \times 10^{-5}\right.$ to $\left.1.8 \times 10^{-3} \mathrm{msec}^{-1}\right)$ depends on the presence of inter connected extrinsic macropores $(2-200 \mu \mathrm{m})$. Thus the flow-rate enhances with the number of macropores present in the foam matrix. At low pressure (20 to $1 \mathrm{~Pa}$ ), the water only flows through the larger macroporous voids, which further suggests the importance of the induction of macropores inside the COF matrix for pollutant adsorption.

\section{CONCLUSION}

We have successfully overcome the difficulty in the 3Dprinting of crystalline organic materials with ordered and disordered pores in the matrix. Herein, we have demonstrated a strategy to create the $3 \mathrm{D}$ macro-architecture of crystalline and porous COF-GO foams. The hierarchical inclusion of macropores employing graphene oxide as a foaming agent in a $\mathrm{COF}$ matrix renders crystalline and porous $3 \mathrm{D}$ printed COFGO foams. The good shear-thinning and optimum viscosity of the precursor paste allow us to perform software-controlled 3D-printing of the material in different shapes and in multiple layers. The 3D-printed COF-GO foams possess a hierarchical order of continuous porosity in a size regime over six orders of magnitude $\left(10^{-9}\right.$ to $\left.10^{-3} \mathrm{~m}\right)$. The interconnected macroporous matrix decorated with intrinsic micropores shows an excellent adsorption capability of pollutants from water. The rapid and efficient removal of various organic and inorganic pollutants from water reveals the significance of the induction of macroporous volume into the 2D COF matrix. We believe that the blending of advanced 3D-printing with the COF-GO foams can pave the way to the discovery of a leading water purification material at an industrial level soon.

\section{ASSOCIATED CONTENT}

Supporting Information. Synthesis, crystallography and characterization details are provided in Supporting Information file. This material is available free of charge via the Internet at http://pubs.acs.org.

\section{AUTHOR INFORMATION}

\section{Corresponding Author}

* r.banerjee@ncl.res.in

\section{Author Contributions}

\section{Notes}

The authors declare no competing financial interests.

\section{ACKNOWLEDGMENT}

AKM \& SK acknowledge UGC and FK \& AH acknowledge CSIR for SRF. RB. acknowledges IISER-Kolkata start-up grant, DST-Swarna Jayanti Fellowship grant (DST/SJF/CSA-02/20162017), and DST Mission Innovation (DST/TM/EWO/MI/CCUS/17 and DST/TMD(EWO)/IC52018/01(C)) for funding. We acknowledge Dr. Mehdi Azimian (Math2MarketGmbH) for the short-term license to PoroDict software module. We acknowledge Dr. Guruswamy Kumaraswamy for the PXRD and 3D-printing facilities. We acknowledge Dr. Suresh Bhat for the confocal fluorescence microscopy. The authors also thank Dr. Tapan Pal and Mr. Kiran Asokhan for their help in some of the reactions and experiments.

\section{REFERENCES}

1. (a) Cote, A. P.; Benin, A. I.; Ockwig, N. W.; Matzger, A. J.; O'Keeffe, M.; Yaghi, O. M. Porous, Crystalline, Covalent Organic Frameworks. Science 2005, 310, 1166-1170. (b) Kuhn, P.; Antonietti, M.; Thomas, A. Porous, Covalent Triazine Based Frameworks Prepared by Ionothermal Synthesis. Angew. Chem. Int. Ed. 2008, 47, 3450-3453. (c) Ding, S.-Y.; Wang, W. Covalent organic frameworks (COFs): from design to applications. Chem. Soc. Rev. 2013, 42, 548-568. (d) Wang, S.; Wang, Q.; Shao, P.; Han, Y.; Gao, X.; Ma, L.; Yuan, S.; Ma, X.; Zhou, J.; Feng, X.; Wang, B. Exfoliation of Covalent Organic Frameworks into Few-Layer Redox-Active Nanosheets as Cathode Materials for Lithium-Ion Batteries. J. Am. Chem. Soc. 2017, 139, 4258-4261. (e) Crowe, J. W.; Baldwin, L. A.; McGrier, P. L. Luminescent Covalent Organic Frameworks Containing a Homogeneous and Heterogeneous Distribution of Dehydrobenzoannulene Vertex Units. J. Am. Chem. Soc. 2016, 138, 10120-10123. (f) Sun, A.; Aguila, B.; Perman, J.; Nguyen, N.; Ma, S. Flexibility Matters: Cooperative Active Sites in Covalent Organic Framework and Threaded Ionic Polymer. J. Am. Chem. Soc. 2016, 138, 15790-15796. (g) Han, X.; Xia, Q.; Huang, J.; Liu, Y.; Tan, C.; Cui, Y. Salen-Based Covalent Organic Framework. J. Am. Chem. Soc. 2017, 139, 8693-8697. (h) Liu, X-H.; Guan, C-Z.; Ding, S-Y.; Wang, W.; Yan, H-J.; Wang, D.; Wan, L-J. On-Surface Synthesis of Single-Layered TwoDimensional Covalent Organic Frameworks via Solid-Vapor Interface Reactions. J. Am. Chem. Soc. 2013, 135, 10470-10474. 
(i) Dogru, M.; Sonnauer, A.; Gavryushin, A.; Knochel, P.; Bein, T. A Covalent Organic Framework with $4 \mathrm{~nm}$ Open Pores. Chem. Commun. 2011, 47, 1707-1709. (j) Stegbauer, L.; Schwinghammer, K.; Lotsch, B. V. A Hydrazone-Based Covalent Organic Framework for Photocatalytic Hydrogen Production. Chem. Sci. 2014, 5, 2789-2793. (k) Wei, S.; Zhang, F.; Zhang, W.; Qiang, P.; Yu, K.; Fu, X.; Wu, D.; Bi, S.; Zhang, F. Semiconducting 2D Triazine-Cored Covalent Organic Frameworks with Unsubstituted Olefin Linkages. J. Am. Chem. Soc. 2019, 141, 14272-14279. (1) Diercks, C. S.; Yaghi, O. M. The atom, the molecule, and the covalent organic framework. Science 2017, 355, 923

2. (a) Kandambeth, S.; Mallick, A.; Lukose, B.; Mane, M. V.; Heine, T.; Banerjee, R. Construction of Crystalline 2D Covalent Organic Frameworks with Remarkable Chemical (Acid/Base) Stability via a Combined Reversible and Irreversible Route. J. Am. Chem. Soc. 2012, 134, 19524-19527. (b) Karak, S.; Kandambeth, S.; Biswal, B. P.; Sasmal, H. S.; Kumar, S.; Pachfule, P.; Banerjee, R. Constructing Ultraporous Covalent Organic Frameworks in Seconds via an Organic Terracotta Process. J. Am. Chem. Soc. 2017, 139, 1856-1862. (c) Halder, A.; Karak, S.; Addicoat, M.; Bera, S.; Chakraborty, A.; Kunjattu, S. H.; Pachfule, P.; Heine, T.; Banerjee, R. Ultrastable Imine-Based Covalent Organic Frameworks for Sulfuric Acid Recovery: An Effect of Interlayer Hydrogen Bonding. Angew. Chem., Int. Ed. 2018, 57, 5797-5802. (d) Xu, H.; Gao, J.; Jiang, D. Stable, crystalline, porous, covalent organic frameworks as a platform for chiral organocatalysts. Nat. Chem. 2015, 7, 905-912.

3. (a) DeBlase, C. R.; Silberstein, K. E.; Truong, T. T.; Abruna, H. D.; Dichtel, W. R. $\beta$-Ketoenamine-Linked Covalent Organic Frameworks Capable of Pseudocapacitive Energy Storage. J. Am. Chem. Soc. 2013, 135, 16821-16824. (b) Lin, S.; Diercks, C. S.; Zhang, Y.-B.; Kornienko, N.; Nichols, E. M.; Zhao, Y.; Paris, A. R.; Kim, D.; Yang, P.; Yaghi, O. M.; Chang, C. J. Covalent Organic Frameworks Comprising Cobalt Porphyrins for Catalytic $\mathrm{CO}_{2}$ Reduction in Water. Science 2015, 349, 1208. (c) Ding, S.-Y.; Gao, J.; Wang, Q.; Zhang, Y.; Song, W.-G.; Su, C.Y.; Wang, W. Construction of Covalent Organic Framework for Catalysis: Pd/COF-LZU1 in Suzuki-Miyaura Coupling Reaction. J. Am. Chem. Soc. 2011, 133, 19816-19822. (d) Mitra, S.; Kandambeth, S.; Biswal, B. P.; Khayum M., A.; Choudhury, C. K.; Mehta, M.; Kaur, G.; Banerjee, S.; Prabhune, A.; Verma, S.; Roy, S.; Kharul, U. K.; Banerjee, R. Self-exfoliated Guanidinium-based Ionic Covalent Organic Nanosheets (iCONs). J. Am. Chem. Soc. 2016, 138, 2823-2828. (e) Sun, Q.; Aguila, B.; Perman, J.; Earl, L. D.; Abney, C. W.; Cheng, Y.; ei, H.; Nguyen, N.; Wojtas, L.; Ma, S. Postsynthetically Modified Covalent Organic Frameworks for Efficient and Effective Mercury Removal. J. Am. Chem. Soc. 2017, 139, 2786-2793. (f) Khayum M., A..; Ghosh, M.; Vijayakumar, V.; Halder, A.; Nurhuda, M.; Kumar, S.; Addicoat, M.; Kurungot, S.; Banerjee, R. Zinc Ion Interactions in a Two-Dimensional Covalent Organic Framework Based Aqueous Zinc Ion Battery. Chemical Science 2019, 10, 8889-8894. (g) Yan, S.; Guan, X.; Li, H.; Li, D.; Xue, M.; Yan, Y.; Valtchev, V.; Qiu, S.; Fang, Q. Threedimensional Salphen-based Covalent-Organic Frameworks as Catalytic Antioxidants. J. Am. Chem. Soc. 2019, 141, 2920-2924.

4. (a) Huang, N.; Zhai, L.; Xu, H.; Jiang, D. Stable Covalent Organic Frameworks for Exceptional Mercury Removal from Aqueous Solutions. J. Am. Chem. Soc. 2017, 139, 2428-2434. (b) Hao, D.; Zhang, J.; Lu, H.; Leng, W.; Ge, R.; Dai, X.; Gao, Y. Fabrication of a COF-5 Membrane on a Functionalized $\alpha$ $\mathrm{Al}_{2} \mathrm{O}_{3}$ Ceramic Support Using a Microwave Irradiation Method. Chem. Commun. 2014, 50, 1462-1464. (c) Dey, K.; Pal, M.; Rout, K. C.; Kunjattu, H. S.; Das, A.; Mukherjee, R.; Kharul, U. K.; Banerjee, R. Selective Molecular Separation by Interfacially Crystallized Covalent Organic Framework Thin Films. J. Am. Chem. Soc. 2017, 139, 13083-13091. (d) Jiang, Y.; Liu, C.; Huang, A. EDTA-Functionalized Covalent Organic Framework for the Removal of Heavy-Metal Ions. ACS Appl. Mater. Inter- faces 2019, 11, 32186-32191. (e) Huang, J.; Han, X.; Yang, S.; Cao, Y.; Yuan, C.; Liu, Y.; Wang, J.; Cui, Y. Microporous 3D Covalent Organic Frameworks for Liquid Chromatographic Separation of Xylene Isomers and Ethylbenzene. J. Am. Chem. Soc. 2019, 141, 8996-9003. (f) Li, Y.; Wang, C.; Ma, S.; Zhang, H.; Ou, J.; Wei, Y.; Ye, M. Fabrication of Hydrazone-Linked Covalent Organic Frameworks Using Alkyl Amine as Building Block for High Adsorption Capacity of Metal Ions. ACS Appl. Mater. Interfaces 2019, 11, 11706-11714. (g) Yuan, S.; Li, X.; Zhu, J.; Zhang, G.; Puyvelde,P. V.; Bruggen, B. V. Covalent Organic Frameworks for Membrane Separation. Chem. Soc. Rev. 2019, 48, 2665-2681.

5. Karak, S.; Dey, K.; Torris, A.; Halder, A.; Bera, S.; Kanheerampockil, F.; Banerjee, R.; Inducing Disorder in Order: Hierarchically Porous Covalent Organic Framework Nanostructures for Rapid Removal of Persistent Organic. J. Am. Chem. Soc. 2019, 141, 18, 7572-7581.

6. (a) Kandambeth, S.; Biswal, B. P.; Chaudhari, H. D.; Rout, K. C.; Kunjattu, H. S.; Mitra, S.; Karak, S.; Das, A.; Mukherjee, R.; Kharul, U. K.; Banerjee, R. Selective Molecular Sieving in SelfStanding Porous Covalent-Organic-Framework Membranes. Adv. Mater. 2017, 29, 1603945-1603953. (b) Zhang, M.; Li, L.; Lin, Q.; Tang, M.; Wu, Y.; Ke, C. Hierarchical-CoassemblyEnabled 3D-Printing of Homogenous and Heterogeneous Covalent Organic Frameworks. J. Am. Chem. Soc. 2019, 141, 5154-5158. (c) Rodríguez-San-Miguel, D.; Abrishamkar, A.; Navarro, J. A. R.; Rodriguez-Trujillo, R.; Amabilino, D. B.; Mas-Balleste', R.; Zamora, F.; Puigmartı'-Luis, J, Crystalline Fibres of a Covalent Organic Framework through Bottom-up Microfluidic Synthesis. Chem.Commun. 2016, 52, 9212-9215.

7. (a) Zhang, Q.; Zhang, F.; Medarametla, S. P.; Li, H.; Zhou, C.; Lin, D. 3D Printing of Graphene Aerogels. Small 2016, 12, 1702-1708. (b) Yao, Y.; Fu, K. K.; Yan, C.; Dai, J.; Chen, Y.; Wang, Y.; Zhang, B.; Hitz, E.; Hu, L. Three-Dimensional Printable High-Temperature and High-Rate Heaters. ACS Nano 2016, 10, 5272-5279. (c) ) Kim, J. H.; Lee, S.; Wajahat, M.; Jeong, H.; Chang, W. S.; Jeong, H. J.; Yang, J.-R.; Kim, J. T.; Seol, S. K. Three-Dimensional Printing of Highly Conductive Carbon Nanotube Microarchitectures with Fluid Ink. ACS Nano 2016, 10, 8879-8887. (d) Zhu, C.; Han, T. Y. J.; Duoss, E. B.; Golobic, A. M.; Kuntz, J. D.; Spadaccini, C. M.; Worsley, M. A. Highly compressible $3 \mathrm{D}$ periodic graphene aerogel microlattices. Nat. Commun. 2015, 6, 6962. (e) Lim,G. J. H.; Wu, Y.; Shah, B. B.; Koh, J. J.; Liu, C. K.; Zhao, D.; Cheetham, A. K.; Wang, J.; Ding, J. 3D-Printing of Pure Metal-Organic Framework Monoliths. ACS Materials Lett. 2019, 1, 147-153. (f) Lahtinen, E; Precker, R. L. M.; Lahtinen, M.; Hey-Hawkins, E.; Haukka, M. Selective Laser Sintering of Metal-Organic Frameworks: Production of Highly Porous Filters by 3D Printing onto a Polymeric Matrix. ChemPlusChem 2019, 84, 222-225. (g) Thakkar, H.; Eastman, S.; Al-Naddaf, Q.; Rownaghi, A. A.; Rezaei, F. 3DPrinted Metal-Organic Framework Monoliths for Gas Adsorption Processes. ACS Appl. Mater. Interfaces 2017, 9, 35908-35916. (h) Dhainaut, J.; Bonneau, M.; Ueoka, R.; Kanamori, K.; Furukawa, S. Formulation of Metal-Organic Framework Inks for the 3D Printing of Robust Microporous Solids toward High-Pressure Gas Storage and Separation. ACS Appl. Mater. Interfaces 2020, 12, 10983-10992. (i) Thakkar, H.; Eastman, S.; Hajari, A.; Rownaghi, A. A.; Knox, J. C.; Rezaei, F. 3D-Printed Zeolite Monoliths for $\mathrm{CO}_{2}$ Removal from Enclosed Environments. ACS Appl. Mater. Interfaces 2016, 8, 27753-27761. (j) Evans, K. A.; Kennedy, Z. C.; Arey, B. W.; Christ, J. F.; T. Schaef, H. T.; Satish K. Nune, S. K.; Erikson, R. L. Chemically Active, Porous 3D-Printed Thermoplastic Composites. ACS Appl. Mater. Interfaces 2018, 10, 15112-15121. (k) Lefevere, J.; Mullens, S.; Meynen, V. The Impact of Formulation and 3D-printing on the Catalytic Properties of ZSM-5 Zeolite. Chem. Eng. 2018, 349, 260-268.

8. (a) García-Tuñon, E.; Barg, S.; Franco, J.; Bell, R.; Eslava, S.; D'Elia, E.; Maher, R. C.; Guitian, F.; Saiz, E. Printing in Three Dimensions with Graphene. Adv. Mater. 2015, 27, 1688-1693. 
(b) Ma, Y.; Yue, Y.; Zhang, H.; Cheng, F.; Zhao, W.; Rao, J.; Luo, S.; Wang, J.; Jiang, X.; Liu, Z.; Liu, N.; Gao, Y. 3D Synergistical MXene/Reduced Graphene Oxide Aerogel for a Piezoresistive Sensor. ACS Nano 2018, 12, 3209-3216. (c) Tang, X.; Zhou, H.; Cai, Z.; Cheng, D.; He, P.; Xie, P.; Zhang, D.; Fan, T. Generalized 3D Printing of Graphene-Based Mixed Dimensional Hybrid Aerogels. ACS Nano 2018, 12, 3502-3511.

9. (a) Huang, H.; Chen, P.; Zhang, X.; Lu, Y.; Zhan, W. Edge-toEdge Assembled Graphene Oxide Aerogels with Outstanding Mechanical Performance and Superhigh Chemical Activity. Small 2013, 9, 1397-1404. (b) Shen, Y.; Fang, Q. L.; Chen, B. L. Environmental Applications of Three- Dimensional Grphenebased Macrostructures: Adsorption, Transformation, and Detection. Environ. Sci. Technol. 2015, 49, 67-84.

10. (a) Inadera, H. Neurological Effects of Bisphenol A and its Analogues. Int. J. Med. Sci., 2015, 12, 926-936. (b) Konieczna, A.; Rutkowska, A.; Rachon, D. Health Risk of Exposure to Bisphenol A (BPA). Rocz. Panstw. Zakl. Hig. 2015, 66, 5-11.

11. (a) Kyle, S.; Jessop, Z. M.; Al-Sabah, A.; Whitaker, I. S. 'Printability' of Candidate Biomaterials for Extrusion Based 3d Printing: State-of-the-art. Adv. Healthcare Mater. 2017, 6, 1700264. (b) Guo, Y.; Patanwala, H. S.; Bognet, B.; Ma, A. W. K. Inkjet and Inkjet-based 3D Printing: Connecting Fluid Properties and Printing Performance. Rapid Prototyp. J. 2017, 23, 562-576.

12. (a) Karak, S.; Kumar, S.; Pachfule, P.; Banerjee, R. Porosity Prediction through Hydrogen Bonding in Covalent Organic Frameworks. J. Am. Chem. Soc. 2018, 140, 5138-5145.

13. Qu, J. H. Research Progress of Novel Adsorption Processes in Water Purification: A Review. J. Environ. Sci. 2008, 20, 1-13.
14. (a) Ho, Y. S.; McKay, G. Pseudo-second Order Model for Sorption Processes. Process Biochem. 1999, 34, 451-465. (b) Alsbaiee, A.; Smith, B. J.; Xiao, L.; Ling, Y.; Helbling, D. E.; Dichtel, W. R. Rapid Removal of Organic Micropollutants from Water by a Porous $\beta$-cyclodextrin Polymer. Nature, 2016, 529, 190-194.

15. (a) Putra, E. K.; Pranowo, R.; Sunarso, J.; Indraswati, N.; Ismadji, S. Performance of Activated Carbon and Bentonite for Adsorption of Amoxicillin from Wastewater: Mechanisms, Isotherms and Kinetics. Water Res. 2009, 43, 2419-2430. (b) Wan Ngah, W. S.; Teong, L. C.; Hanafiah, M. A. K. M. Adsorption of Dyes and Heavy Metal ions by Chitosan Composites: A Review. Carbohydr. Polym. 2011, 83, 1446-1456. (c) Wang, R. Z.; Huang, D. L.; Liu, Y. G.; Peng,Z. W.; Zeng, G. M.; Lai,C.; Xu, P.; Huang, C.; Zhang, C.; Gong, X. M. Selective Removal of BPA from Aqueous Solution Using Molecularly Imprinted Polymers based on Magnetic Graphene Oxide. RSC Adv. 2016, 6 , 106201-106210. (d) Sui, Q.; Huang, J.; Liu, Y. S.; Chang, X. F.; Ji, G. B.; Deng, S. B.; Xie, T.; Yu, G. Rapid Removal of Bisphenol A on Highly Ordered Mesoporous Carbon. J. Environ. Sci. 2011, 23, 177-182. (e) Cao, F.; Bai, P.; Li, H.; Ma, Y.; Deng, X.; Zhao, C. Preparation of PolyethersulfoneOrganophilicMontmorillonite Hybrid Particles for the Removal of Bisphenol A. J. Hazard. Mater. 2009, 162, 791-798. (f) Wang, P.; Xiao, P.; Zhong, S.; Chen, J.; Lin, H.; Wu, X.-L. Bamboo-like Carbon Nanotubes Derived from Colloidal Polymer Nanoplates for Efficient Removal of Bisphenol A. J. Mater. Chem. A, 2016, 4, 15450-15456. 
Table of contents

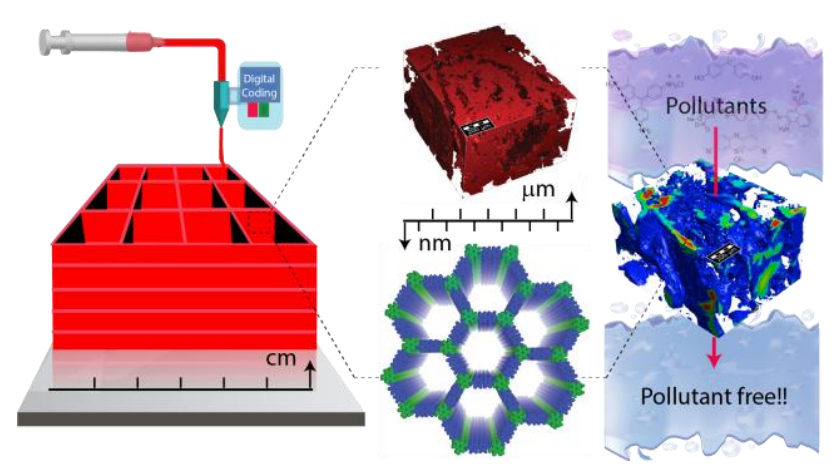




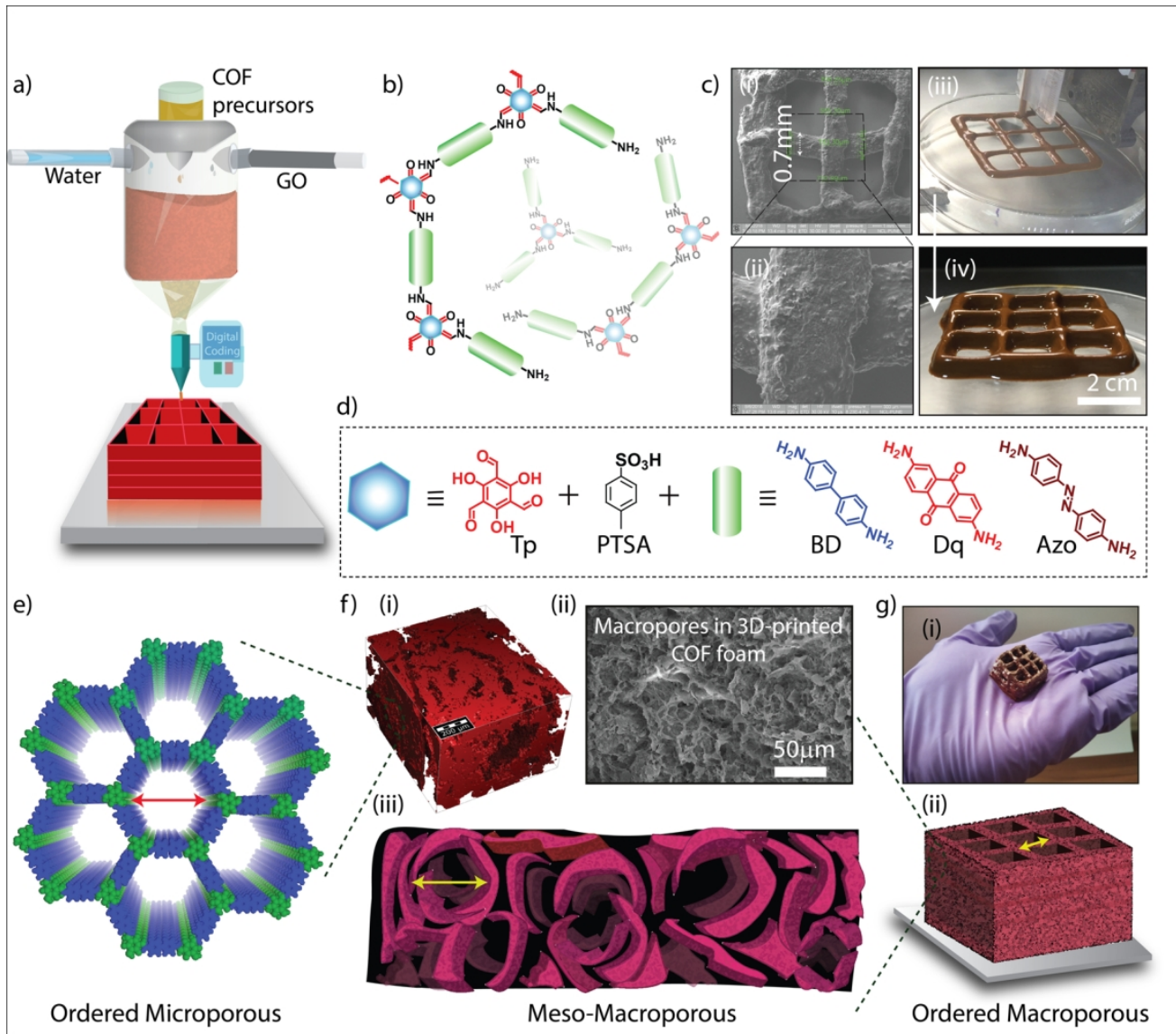

Figure 1

$299 \times 263 \mathrm{~mm}(150 \times 150 \mathrm{DPI})$ 

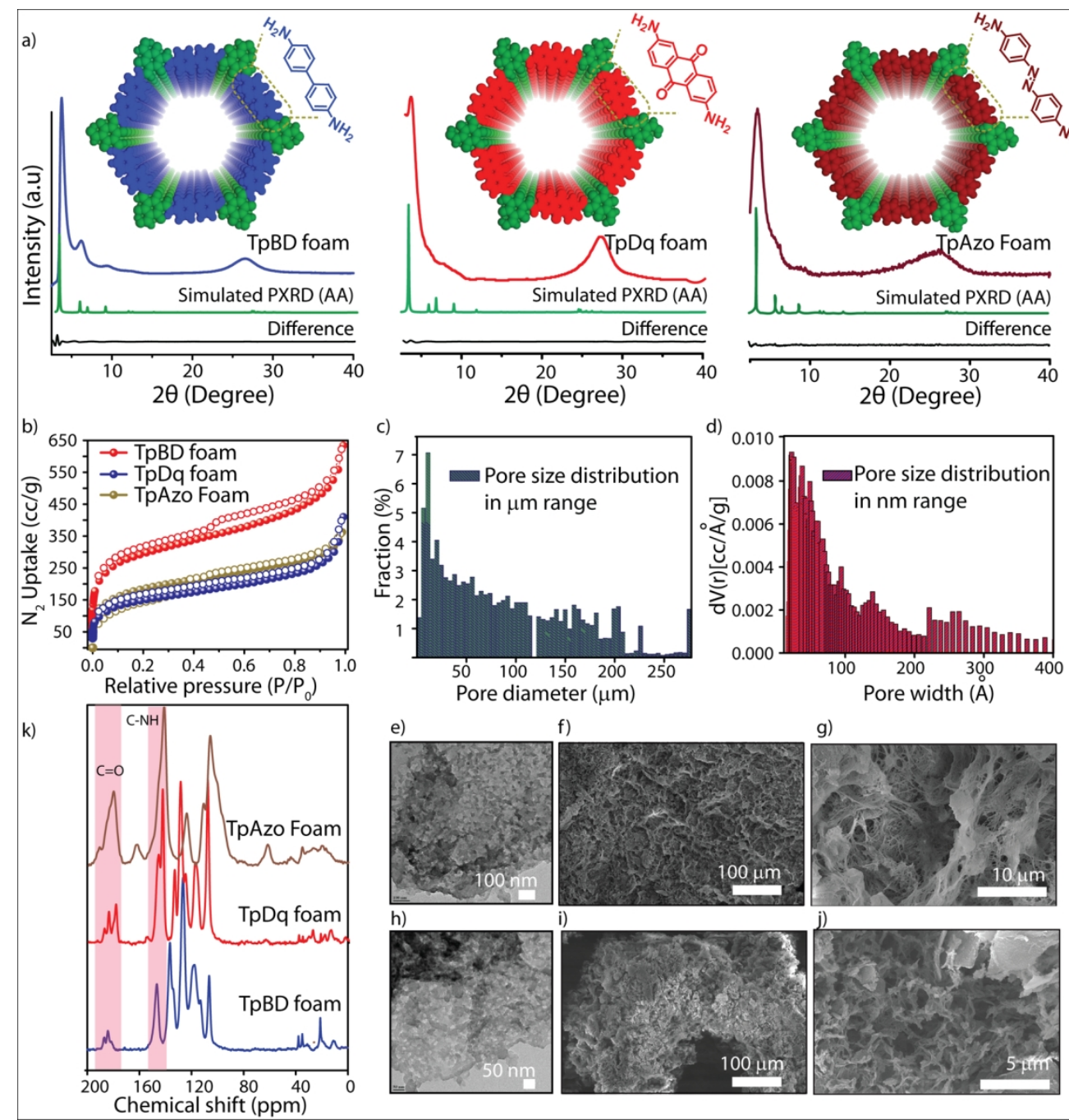

Figure 2

$295 \times 307 \mathrm{~mm}(150 \times 150 \mathrm{DPI})$ 


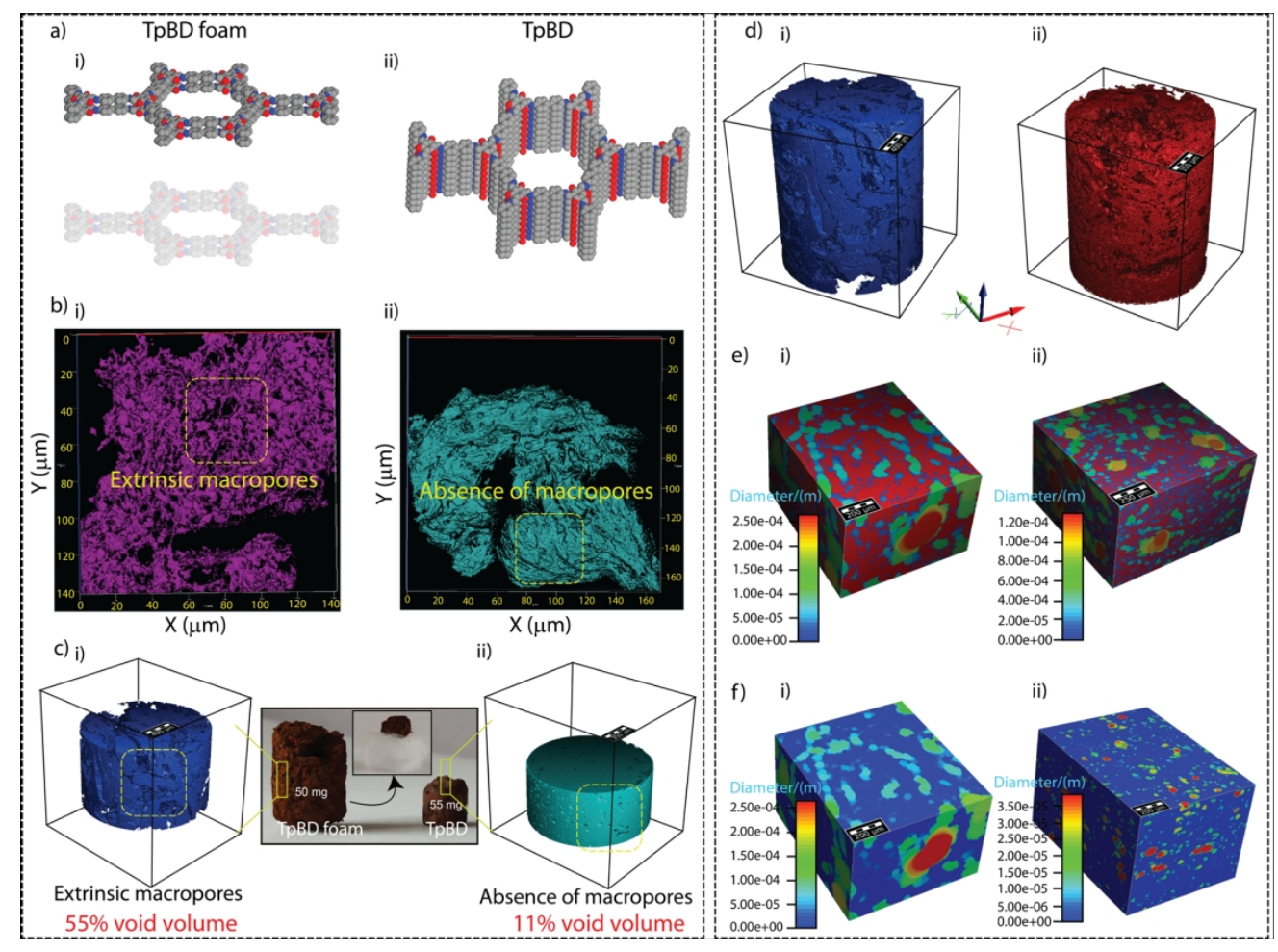

Figure 3

$311 \times 229 \mathrm{~mm}(150 \times 150 \mathrm{DPI})$ 

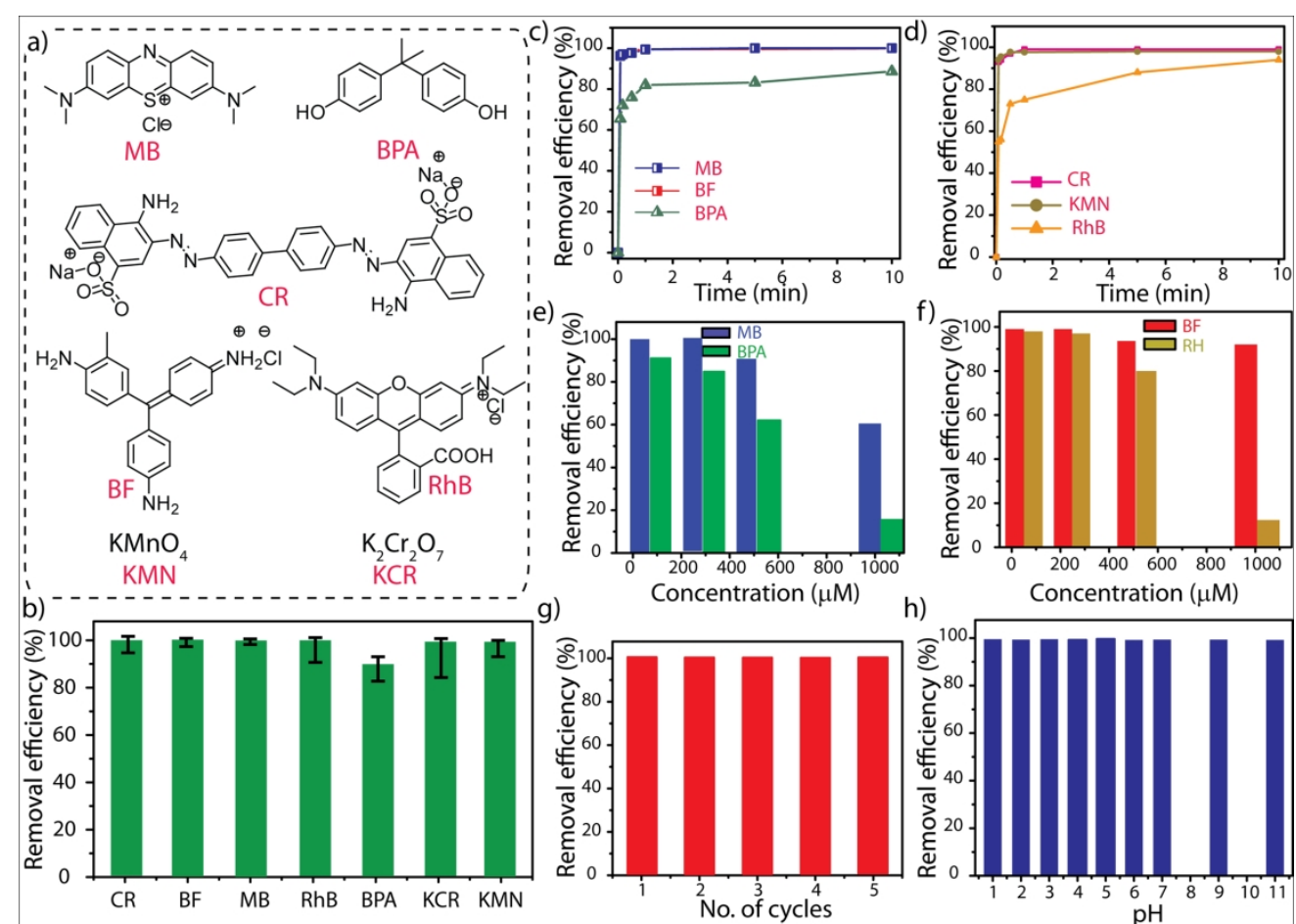

Figure 4

$372 \times 267 \mathrm{~mm}(150 \times 150 \mathrm{DPI})$ 

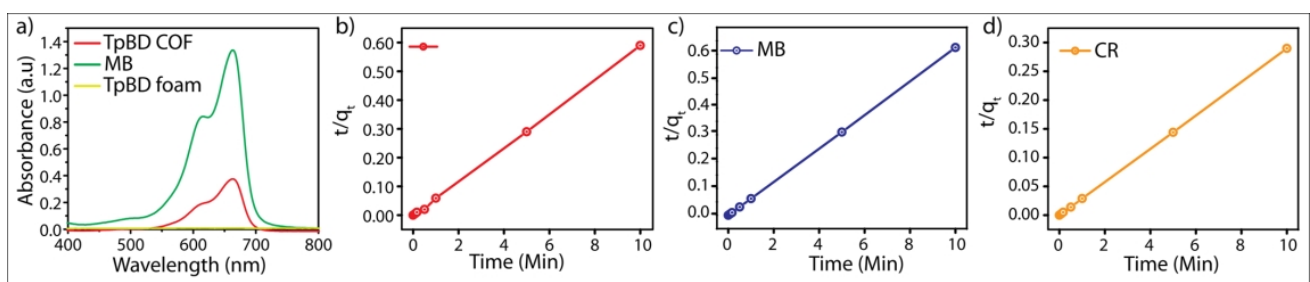

e)
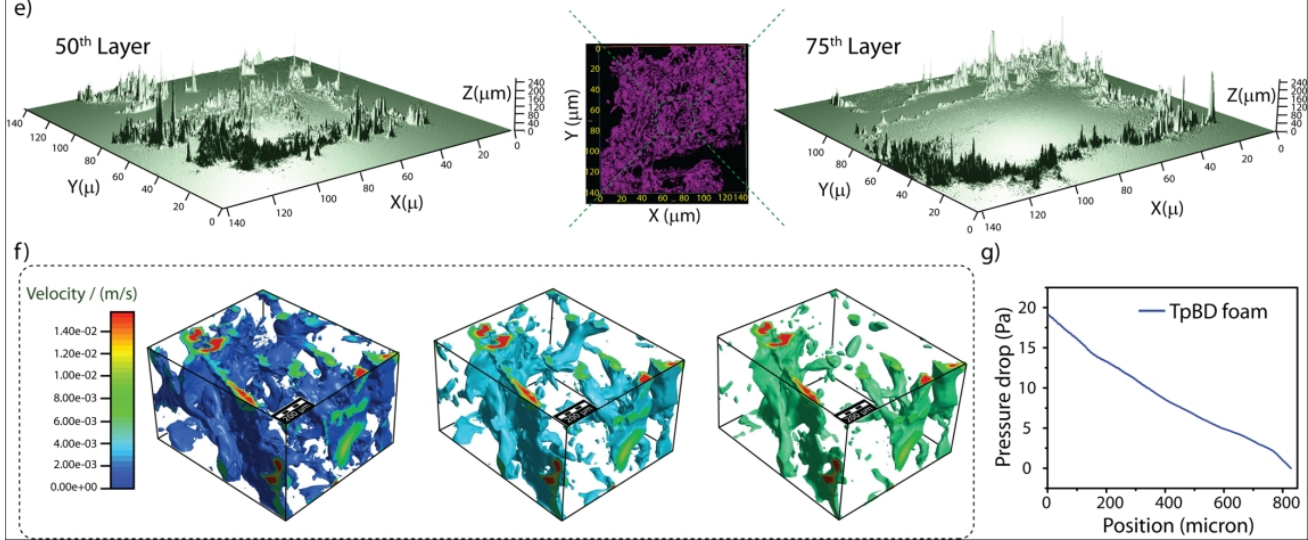

Figure 5

$356 \times 224 \mathrm{~mm}(150 \times 150 \mathrm{DPI})$ 


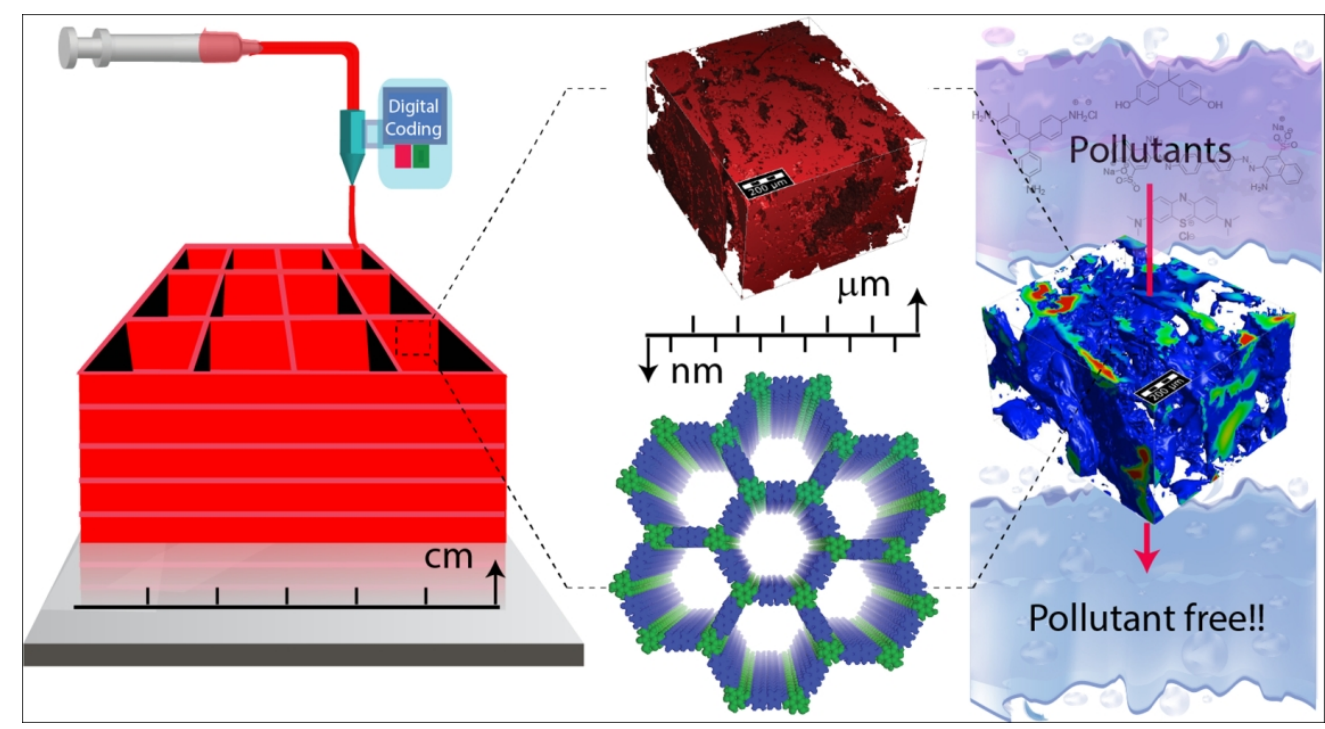

Figure_TOC

$330 \times 179 \mathrm{~mm}(124 \times 124 \mathrm{DPI})$ 